\title{
ESTUDO COMPARATIVO DA OCLUSÃO E DA SUA RELAÇÃO COM AS DISFUNÇÕES \\ TEMPOROMANDIBULARES (DTM) EM JOVENS COM E SEM TRATAMENTO ORTODÔNTICO
}

KARYNA MARTINS DO VALLE

Dissertação apresentada à Faculdade de Odontologia de Bauru, da Universidade de São Paulo, como parte dos requisitos para obtenção do título de Mestre em Ortodontia.

Orientador: Prof. Dr. Arnaldo Pinzan 


\begin{tabular}{|l|}
\hline V24e \\
Valle, Karyna Martins do \\
Estudo comparativo da oclusão e da sua \\
relação com as Disfunções Temporomandibulares (DTM) \\
em jovens com e sem tratamento ortodôntico / Karyna \\
Martins do Valle. - Bauru, 2000. \\
134p.: il.; 29,7cm \\
Dissertação. (Mestrado) - Faculdade de \\
Odontologia de Bauru. USP. \\
Orientador: Prof. Dr. Arnaldo Pinzan
\end{tabular}

Autorizo, exclusivamente para fins acadêmicos e científicos, a reprodução total ou parcial desta dissertação, por processos fotocopiadores e/ou meios eletrônicos.

Assinatura do autor (a):

Data: 
17 de agosto de 1974

$1993-1996$

$1997-1998$

$1998-2000$

Associações
Nascimento - Bauru, SP.

Faculdade de Odontologia de Bauru, USP.

Curso de Aperfeiçoamento em Oclusão e Disfunção Craniomandibular.

Curso de Pós-Graduação em Ortodontia, ao nível de Mestrado, na Faculdade de Odontologia de Bauru.

Associação Paulista de Cirurgiões Dentistas 
Ao Senhor da minha vida, Santo e Eterno

Dens, merecedor de toda a honra e glória, que me acompanha a cada momento, sempre fiel, derramando Sua graça e amor, concedendo-me infinitas bênçãos. 
Aos mens pais, Accacio e Tânia, que com amor, carinho e muita dedicação, ajudaram-me a traçar os mens caminhos com sábias orientaçóes, sendo constantemente exemplos de vida.

Aos mens irmãos, Caío e Larissa, que com muita alegria sempre me acompanharam e com amizade fiel me apoiaram neste trabalho.

Ao Mauro, pelo amor e carinho a mim dedicado, que sempre com paciência e compreensão me incentivou nesta etapa da vida.

Dedico este trabalho. 
Aos professores

\section{Doutor Arnaldo Pinzan}

Agradeço os ensinamentos valiosos, a confiança e a orientação deste trabalho.

Obrigada pelo exemplo de conduta profissional e pelo convívio fraterno e amigo, que serviram-me de estímulo durante estes anos de convivência 


\section{Doutor Paulo César Rodrigues Conti}

Agradeço a disposição, a colaboração e os ensinamentos na execução desta pesquisa.

Obrigada pelo constante incentivo e pela amizade, mostrando-se sempre pronto a me ajudar.

\section{Doutor Gerson Bonfante}

Agradeço toda a atenção e ensinamentos que, transmitidos com muito carinho, enriqueceram este trabalho.

Obrigada por toda dedicação e fraternidade que me ajudaram profissional e pessoalmente.

O meu profundo reconhecimento e respeito. 


\section{AGRADECIMENTOS ESPECIAIS}

A todos os meus familiares que sempre me dedicaram amor e atenção.

Aos meus avós Accácio, Nilda e João que nunca esqueceram de mim em suas orações.

À Ana Aida pelo companheirismo e pelos ensinamentos prestados desde o início da minha graduação.

A todos os meus amigos e irmãos em Cristo, que me sustentaram em oração durante a execução deste trabalho. 


\section{AGRADECIMENTOS}

Aos Professores Doutores da Disciplina de Ortodontia da Faculdade de Odontologia de Bauru,

Prof. Dr. DÉCIO RODRIGUES MARTINS,

Prof. Dr. RENATO RODRIGUES DE ALMEIDA,

Prof. Dr. JOSÉ FERNANDO CASTANHA HENRIQUES,

Prof. Dr. MARCOS ROBERTO DE FREITAS,

Prof. Dr. ARNALDO PINZAN

Prof. Dr. GUILHERME DOS REIS PEREIRA JANSON,

e às suas respectivas famílias,

pelos ensinamentos e experiências transmitidos, pelo incentivo e apoio constantes, e pela confiança e carinho a mim dispensados. 
Ao Professor Doutor Aymar Pavarini, diretor desta Faculdade, pelo incentivo transmitido.

Ao Professor Doutor Luiz Fernando Pegoraro, Presidente da Comissão de Pós-Graduação da FOB-USP, pela compreensão e amizade.

Aos Professores Doutores desta Faculdade, pela orientação e motivação transmitidos durante toda a minha formação acadêmica.

Ao amigos do Curso de Mestrado, Ana Carla, Daniela, Danilo, Fausto, Karina, Paulo, Renata e Roberto por todos os momentos que passamos juntos, pelo carinho, amizade e respeito durante estes anos.

À Ana Claudia pelo companheirismo e incentivo que tornaram possível a execução deste trabalho.

Aos amigos do Curso de Doutorado, Acácio, Alexandre, Liliana, Márcio, Maria Helena e Ricardo, pelo convívio e amizade.

Aos amigos Eduardo e Marcinha, pelo carinho e incentivo. 
Aos funcionários da Disciplina de Ortodontia, Maria José dos Santos Formeti (Tia Maria), Tereza Cristina Alvez Camaforte Ducatti, Cristiane de Jesus Cano, Vera Lúcia Rodrigues Purgato, Luiz Sérgio Vieira e Daniel Francisco Rascão Selmo (Bonné), por toda a amizade e atenção durante o nosso convívio.

Às funcionárias da Pós-Graduação, Ana Maria Machado Bocchio, Cleusa Gonçalves Leite, Giane Tenório Quintela e Heloísa Ferreira da Silva que sempre me dispensaram atenção e carinho.

Aos funcionários da Biblioteca pelo carinho e amizade com que sempre me atenderam.

Aos funcionários desta Faculdade pela dedicação a mim transmitidos.

Aos pacientes da Graduação e Pós-Graduação pela colaboração para minha formação.

Ao CNPq pela concessão da bolsa de estudos que viabilizou a execução desta pesquisa. 
LISTA DE FIGURAS ......................................................... xii

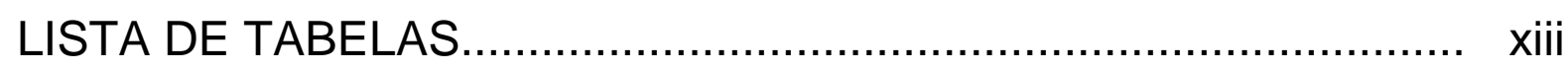

LISTA DE ABREVIATURAS ................................................ $x v$

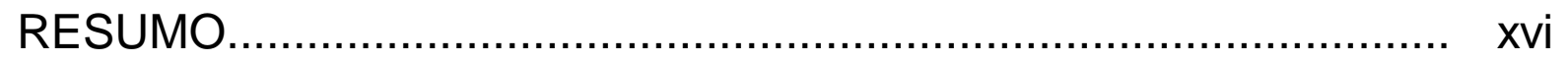

1 - INTRODUÇÃO .............................................................. 1

2 - REVISÃO DA LITERATURA .......................................... 6

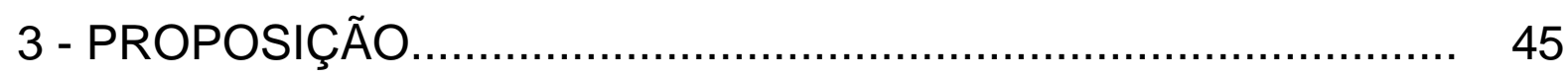

4 - MATERIAL E MÉTODOS ............................................... 48

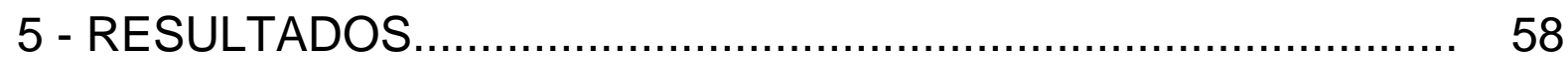

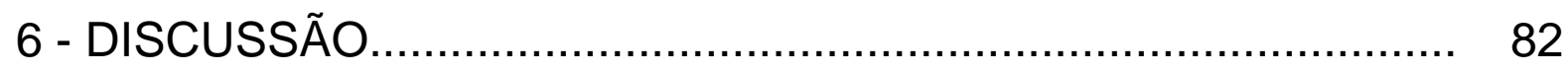

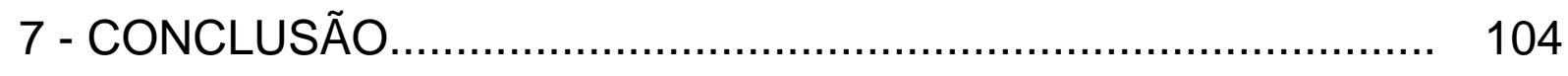

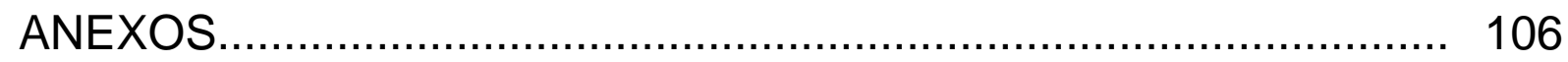

REFERÊNCIAS BIBLIOGRÁFICAS ........................................ 112

ABSTRACT .................................................................. 133 


\section{LISTA DE FIGURAS}

Figura 5.1 - Gráfico da distribuição da amostra, dividida por grupos, em relação ao índice de DTM

Figura 5.2 - Correlação entre o overbite e o grau de DTM

Figura 5.3 - Correlação entre o overjet e o grau de DTM.

Figura 5.4 - Gráfico da relação entre a discrepância de RC 77 para MIH e o índice de DTM

Figura 5.5 - Gráfico da relação entre guia anterior e DTM 


\section{LISTA DE TABELAS}

Tabela 5.1 - Freqüência percentual das respostas do questionário anamnésico pelo grupo I (Classe I sem tratamento ortodôntico)

Tabela 5.2 - Freqüência percentual das respostas do questionário anamnésico pelo grupo II (Classe II sem tratamento ortodôntico)

Tabela 5.3 - Freqüência percentual das respostas do questionário anamnésico pelo grupo III (Classe I com tratamento ortodôntico)

Tabela 5.4 - Freqüência percentual das respostas do questionário anamnésico pelo grupo IV (Classe II com tratamento ortodôntico)

Tabela 5.5 - Distribuição da amostra, dividida por grupos, em relação ao índice de DTM

Tabela 5.6 - Relação entre a mordida aberta anterior (MAA) e o grau de DTM 
Tabela 5.7 - Relação entre a mordida cruzada posterior (MCP) e o grau de DTM

Tabela 5.8 - Relação entre a discrepância de RC para MIH e o grau de DTM

Tabela 5.9 - Relação entre o guia lateral e o grau de DTM 78

Tabela 5.10 - Relação entre o guia anterior e o grau de DTM 79

Tabela 5.11 - Relação entre os contatos oclusais em não80 trabalho e o grau de DTM

Tabela 5.12 - Relação entre o ajuste oclusal e o grau de DTM

Tabela 5.13 - Relação entre as facetas de desgaste e o grau de DTM 


\section{LISTA DE ABREVIATURAS}

ATM - Articulação Temporomandibular.

DTM - Disfunção Temporomandibular.

MIH - Máxima Intercuspidação Habitual.

MAA - Mordida aberta anterior.

MCP - Mordida cruzada posterior.

ORC - Oclusão de Relação Cêntrica.

RC - Relação Cêntrica.

PI - Posição de Intercuspidação.

PR - Posição Retruída. 
Resumo 


\section{RESUMO}

O objetivo deste trabalho foi avaliar a oclusão como fator etiológico na prevalência de Disfunções Temporomandibulares (DTM) em indivíduos tratados e não tratados ortodonticamente. Os 200 casos avaliados foram divididos em quatro grupos, com 50 indivíduos cada. Os grupos I e II, não tratados ortodonticamente, foram constituídos, respectivamente, por jovens com más oclusões de Classes I e II. O grupo III foi constituído por pacientes com má oclusão Classe I e o grupo IV por pacientes com má oclusão Classe II, após o término do tratamento ortodôntico. Os sinais e sintomas de DTM foram avaliados com um questionário anamnésico e pelo exame de palpação muscular e articular, além da detecção de ruídos articulares e análise da movimentação mandibular. $O$ exame da oclusão constou da avaliação do número de contatos em $\mathrm{MIH}$, discrepância entre as posições de $\mathrm{RC}$ e $\mathrm{MIH}$, contatos em lado de não-trabalho, tipos de guia lateral, guia anterior, mordida aberta anterior, mordida cruzada posterior, overjet e overbite, ajuste oclusal e presença de facetas de desgaste. Encontrouse, baseado no questionário anamnésico, uma prevalência de $34 \%$ com DTM leve, 3,5\% com DTM moderada e os outros $62,5 \%$ apresentavamse com ausência de DTM. Não se observou associação entre a severidade de DTM e a realização do tratamento ortodôntico, independente do tipo de má oclusão. Na avaliação da oclusão, o grau de DTM foi associado apenas à ausência de guia anterior. Concluiu-se que a realização do tratamento ortodôntico não se relaciona com a presença de sinais e sintomas de DTM e que a oclusão não pode ser considerada, isoladamente, como fator etiológico. 
Introdução 


\section{1 - INTRODUÇÃO}

As disfunções do sistema estomatognático têm sido alvo de muitas pesquisas no contexto odontológico, provavelmente, devido à grande prevalência destes problemas entre a população. A nomenclatura utilizada para denominar o conjunto de sinais e sintomas característicos destas disfunções, tem se modificado de acordo com os trabalhos que se propõem a explicá-la.

$\operatorname{COSTEN}^{20,21}$, na década de 30 , historicamente, relatou um conjunto de sintomas (problemas auditivos, zumbidos, dor ao redor dos ouvidos e vertigens) e denominou-os como Síndrome de Costen, impulsionando estudos e pesquisas nesta área.

O termo Síndrome Dor-Disfunção da Articulação Temporomandibular foi proposto por SCHWARTZ ${ }^{110}$, que relatou a maior importância do estado psicológico ou fisiológico sobre os fatores desencadeantes, nestas disfunções.

A influência da hiperatividade muscular consagrou 0 termo Síndrome Dor-Disfunção Miofascial $\left(\operatorname{LASKIN}^{65}\right)$. Porém, MCNEILL ${ }^{77}$ propôs: Desordens Craniomandibulares, conhecidas pela sigla DCM, associada ao termo dor orofacial. BELL ${ }^{10}$ sugeriu o termo Desordem Temporomandibular, também conhecido como Disfunção Temporomandibular. 
Por definição, as Disfunções Temporomandibulares abrangem um determinado número de problemas clinicamente distintos que incluem alterações na musculatura mastigatória (músculos masseter, temporal, pterigóideo médio e lateral) e nas articulações temporomandibulares ou em ambos, afetando o sistema estomatognático como um todo, por sinais e sintomas que limitam e incapacitam suas atividades fisiológicas $\left(B E L L^{10}\right)$. Com o intuito de facilitar e esclarecer o entendimento e o diagnóstico das DTM, BELL ${ }^{10}$ realizou uma classificação diagnóstica bem definida: 1) disfunções articulares e 2) não articulares (dos músculos).

Os sintomas observados nas Disfunções Temporomandibulares consistem em: dores na face, dificuldade de abertura da boca, dificuldade nos movimentos mandibulares, dores na ATM, ruídos articulares, dores de cabeça e pescoço ${ }^{19}$.

O exame clínico do paciente possibilita a avaliação dos sinais da DTM, analisando-se a sensibilidade muscular e articular (ATM) à palpação, a restrição da abertura bucal, os estalidos articulares à palpação e as irregularidades nas trajetórias mandibulares ${ }^{53,118}$.

Os distúrbios do sistema mastigatório apresentam uma etiologia multifatorial (AGERBERG; CARLSSON ${ }^{1}, \mathrm{MOHLIN}^{81}$ ) que foi classificada por MCNEILL $^{78}$ como: 1)fatores predisponentes, 2)iniciadores ou precipitadores e 3)perpetuadores, com a finalidade de esclarecer o papel de cada fator na progressão das desordens temporomandibulares. 
Muitos pesquisadores têm se empenhado em descobrir qual a relação entre as desordens do sistema mastigatório, e a má oclusão funcional, a má oclusão morfológica, o tratamento ortodôntico, o desgaste oclusal seletivo, a parafunção e os fatores pscicoemocionais.

Entre as alterações oclusais funcionais encontram-se o desvio entre a posição de relação cêntrica $(R C)$ e a máxima intercuspidação habitual $(\mathrm{MIH})$, contatos em lado de trabalho e nãotrabalho, ausência de guias laterais ou protrusiva, interferências nas guias de desoclusão, entre outros.

As más oclusões Classes I, II, e III de Angle, mordida aberta, mordida cruzada, overjet, overbite, compõem as más oclusões morfológicas que necessitam de tratamento ortodôntico.

Muito embora exista uma corrente com muitos profissionais que afirmam, dogmaticamente, que a oclusão representa um fator predisponente, cientificamente não foi comprovada uma relação direta entre a má oclusão e a Disfunção Temporomandibular.

Durante muitos anos, diversos pesquisadores voltaram suas atenções para a relação existente entre o tratamento ortodôntico e a Disfunção Temporomandibular. Os trabalhos relacionam a ortodontia como causa, cura ou fator preventivo à DTM, contudo não existem dados científicos que comprovem esta relação (PERRY JÚNIOR ${ }^{90}$, RICKETTS $^{98}$; RICKETTS ${ }^{99}$ ). 
As desarmonias oclusais vêm sendo relacionadas às Disfunções Temporomandibulares desde os primeiros estudos a este respeito. Com o avanço das pesquisas, o tratamento ortodôntico, responsável por alterações oclusais, também passou a ser relacionado como um dos fatores causais dos sinais e sintomas das DTM. Desde então, busca-se compreender qual o objetivo do tratamento ortodôntico e sua relação com as desordens do sistema estomatognático. 


\section{Revisão da Literatura}




\section{2 - REVISÃO DA LITERATURA}

A preocupação com os problemas do sistema mastigatório não é um produto dos tempos modernos. Os distúrbios funcionais e as sintomatologias que afligem o sistema estomatognático possuem registros bastante remotos.

No século $V$ a.C., Hipócrates relatou um método de redução de deslocamento da mandíbula semelhante ao utilizado pelos egípcios 2.500 anos antes. O avanço dos conhecimentos anatômicos da mandíbula e da articulação desenvolvidos por Leonardo da Vinci (século $\mathrm{XV}$ ), Andreas Versalius (século XVI) em seu compêndio de anatomia "De Corporis Humanis" em 1543 e John Hunter (século XVIII) permitiram um maior desenvolvimento e confiabilidade dos estudos. Foi nos trabalhos de John Hunter que apareceram as primeiras técnicas cirúrgicas empregadas para as luxações e retenções da mandíbula, com a finalidade de aliviar a disfunção dolorosa da ATM (MIKHAIL; ROSEN $^{80}$ ).

ANNANDALE $^{7}$, em 1887, já relatava procedimentos cirúrgicos para reposicionamento de disco intra-articular em pacientes com limitação dos movimentos mandibulares. O mesmo procedimento foi descrito por PRINGLE ${ }^{91}$ em 1918.

Um dos primeiros ortodontistas a verificar a presença de oclusão traumática em casos tratados ortodonticamente, foi ARNOLD ${ }^{8}$ (1927), atribuindo esta condição ao fato de que interferências oclusais, 
tanto em relação cêntrica como em movimentos funcionais, provocavam problemas periodontais. O ajuste oclusal, que já havia se revelado como terapêutica para estes problemas, foi indicado como complemento ao tratamento ortodôntico, em todos os casos.

Apesar de alguns artigos pioneiros no assunto, a literatura torna clássico o trabalho do otorrinolaringologista Jates $B$. $\operatorname{COSTEN}^{20}$, em 1934, considerada a primeira descrição detalhada da origem e sintomas dos problemas articulares. Seu estudo baseou-se na descrição dos sintomas de 11 pacientes onde incluíam dor ao redor dos ouvidos, zumbidos, dores de cabeça, secura na boca e garganta e ruídos articulares. Este conjunto de sintomas foi caracterizado como síndrome de Costen. O autor acreditava ainda que a perda dos dentes posteriores causava uma sobremordida, resultando em uma pressão dos côndilos nas estruturas retrocondilares. A pressão destas estruturas, principalmente dos vasos e nervos aurículotemporal e do meato acústico externo, resultavam na sintomatologia.

Um dos primeiros trabalhos epidemiológicos nesta área foi desenvolvido por BOMAN ${ }^{14}$, em 1947 examinando 1.350 adultos entre pacientes e funcionários de um hospital sueco, tornando-se a mais freqüente citação em publicações relevantes. Um terço da amostra apresentou sinais de artrose, como crepitação e distúrbios no movimento mandibular, contudo, a dor foi encontrada em apenas $1 \%$ da amostra e não descrita como severa. Seu tratamento consistia na remoção do disco interarticular. 
SICHER ${ }^{115}$, em 1948, questionou a irritação timpânica, argumentando que o único meio de se estimular o nervo corda do tímpano, seria por uma fratura da fissura petrotimpânica.

Ao estudar o ajuste oclusal e outras técnicas de tratamento oclusal, $\operatorname{COBIN}^{18}$, em 1952, observou que o reposicionamento da mandíbula para a relação cêntrica, geralmente, proporcionava um alívio dos sintomas dolorosos na região da articulação temporomandibular.

RICKETTS $^{98}$ (1955) demonstrou a necessidade de harmonizar os movimentos funcionais mandibulares com as estruturas da articulação temporomandibular e com os músculos da mastigação, para prevenir os distúrbios conseqüentes. Estudou o posicionamento dos côndilos nas cavidades glenóide e concluiu que, na maioria dos casos, a oclusão constitui o fator principal relacionado aos distúrbios da articulação temporomandibular e que a musculatura representa a estrutura responsável por estes distúrbios.

SCHWARTZ ${ }^{110}$, em 1955, sugeriu o termo síndrome dordisfunção da ATM e afirmou que sua causa era principalmente a disfunção dos músculos mastigatórios, considerando as anormalidades oclusais apenas fatores contribuintes e os fatores psicogênicos como primários. 
A grande maioria dos trabalhos, até esta época, foi realizada com amostras não padronizadas, sendo pouco representativo da população em geral e por sua vez, sem respeito aos requisitos modernos da investigação epidemiológica na área das DTM. No final da década de 60 , os trabalhos passaram a utilizar uma metodologia mais elaborada podendo retratar a situação das disfunções na população em geral.

Em 1969, LASKIN ${ }^{65}$ propôs uma revisão da síndrome dor-disfunção da ATM de SCHWARTZ ${ }^{110}$ e sugeriu que o espasmo dos músculos mastigatórios seria o fator primário responsável pelos sintomas, passando a utilizar o termo síndrome dor-disfunção miofascial. As causas dessa fadiga muscular seriam hábitos bucais crônicos que agiriam, como mecanismos involuntários de alívio de tensão. Assim, considerou-se a síndrome dor-disfunção como uma doença psicológica, com alterações orgânicas que mais tarde poderiam ser notadas nos dentes e ATMs como um fenômeno secundário. Os fatores como desarmonias oclusais e artrite degenerativa agiriam como perpetuante do processo.

SOLBERG; FLINT; BRANTNER ${ }^{117}$ (1972) propuseramse a verificar se os grupos com desordens no sistema mastigatório diferiam, em níveis de ansiedade, de um grupo controle e se também em relação às características funcionais da oclusão, utilizando o teste "Minnesota Multiphasic Personality Inventory (MMPI)". Os autores avaliaram 29 pacientes com disfunção no sistema mastigatório e 29 indivíduos como grupo controle. Para a avaliação oclusal utilizaram-se 
modelos de gesso montados em articulador semi-ajustável, enquanto a avaliação psicológica ficou a cargo de quatro experientes psicólogos. Os resultados permitiram aos autores concluírem que aproximadamente metade do grupo com sintomas, apresentava maiores índices de ansiedade que o grupo controle e que parece não haver diferenças significantes na oclusão entre os grupos, dentro da metodologia utilizada.

AGERBERG; CARLSSON ${ }^{1}$, ainda em 1972, estudaram a freqüência das desordens funcionais do sistema mastigatório por meio de um questionário enviado por correspondência. A pesquisa avaliou uma amostra de 1.106 pessoas com idade média de 35 anos. Dores faciais e de cabeça foram relatadas por $24 \%$ dos indivíduos, enquanto a restrição do movimento mandibular constou da resposta de $7 \%$ da amostra, sendo mais freqüente nas mulheres, assim como o ruído articular, presente em 39\% dos entrevistados. Os autores concluíram que os dentistas devem se interessar mais pelo diagnóstico e tratamento destas desordens funcionais, devido aos altos índices de disfunção.

Dando continuidade à pesquisa anterior, AGERBERG; CARLSSON $^{2}$, no ano seguinte, formularam um índice baseado nas respostas do trabalho inicial. Os índices demonstraram maiores valores para mulheres, porém as diferenças foram numericamente pequenas. A presença de um único sintoma de disfunção foi encontrado em $57 \%$ e a combinação de dois ou mais, em $30 \%$ da amostra. Concluíram que sintomas de disfunção mastigatória são comuns e de etiologia heterogênea. 
Acreditando na relação da musculatura mastigatória com a interferência oclusal, DAWSON ${ }^{25}$, em 1973, relatou que, ao existir uma interferência oclusal, diversos músculos do sistema mastigatório podem ser envolvidos, principalmente o músculo pterigóideo lateral, apresentando-se com espasmo e sensível à palpação. $O$ autor relatou que o diagnóstico diferencial deve constar da manipulação da mandíbula em relação cêntrica, palpação do músculo pterigóideo lateral e da confecção de "front plateau" (dispositivo que impede o contato entre os dentes), usado por 24 horas. Quando constatada a interferência em relação cêntrica e cessada a sintomatologia dolorosa do músculo após o uso do "front plateau", concluiu-se que as interferências eram as causadoras da sintomatologia apresentada. Neste caso, o autor sugeriu o ajuste oclusal como tratamento para a remissão dos sintomas.

Com o objetivo de investigar as prováveis relações entre as interferências oclusais e a ocorrência do desconforto na ATM e estruturas adjacentes, GEERING ${ }^{40}$, em 1974, avaliou 251 pacientes obtendo histórico e análise oclusal. Verificou uma possível relação entre o deslize de RC para MIH e os sintomas relacionados à ATM em 70 dos pacientes. Contudo, não estabeleceu uma relação entre a magnitude dos deslizes mandibulares e a ocorrência de dor ou outros sintomas. Numa segunda etapa do estudo, verificou a associação entre o deslize e as interferências em não-trabalho e sua relação como a causa principal dos distúrbios do sistema mastigatório. O autor relatou que $40 \%$ dos pacientes apresentaram interferências oclusais não associadas ao deslize e que estes não demonstraram sinais ou sintomas de disfunção. 
GOSS $^{41}$, em 1974, revisou os conceitos relativos à etiologia e diagnóstico da dor-disfunção miofascial. Observou dois grupos envolvidos com esta síndrome: o primeiro composto por indivíduos dos 17 aos 25 anos e dentados e o segundo, composto por pessoas de meia idade e desdentados. $O$ autor afirmou que as mulheres são afetadas quatro vezes mais que os homens e que a síndrome surge a partir de mioespasmos dos músculos da mastigação ocorridos devido a tensão emocional e a má oclusão. Concluiu que existe uma variedade enorme de manifestações clínicas da síndrome, mas as quatro mais importantes, consideradas sinais cardinais, são: a dor, o espasmo muscular, a crepitação auricular e a disfunção muscular.

O grande impulso na área dos estudos epidemiológicos se deu com HELKIMO ${ }^{48,49}$, que em 1974, publicou uma série de trabalhos sobre a função e a disfunção do sistema mastigatório e elaborou um índice anamnésico e um índice clínico de disfunção que mede, quantitativamente, a severidade dos sintomas. Seu índice permite a classificação do paciente pelo índice anamnésico, em três níveis (sem sintomas, médio, severo) e em quatro níveis pelo índice clínico (sem sinais, médio, moderado, severo).

HELKIMO ${ }^{50}$ observou que nos indivíduos onde o índice anamnésico mostrava-se severo, $75 \%$ apresentavam pelo menos um sintoma severo clinicamente e $44 \%$ possuíam dois ou mais. Nos pacientes livres de sintomas, apenas $18 \%$ estavam totalmente assintomáticos clinicamente. Concluiu que o índice realmente mede 0 
que é proposto, sendo de grande valia na identificação das disfunções do sistema mastigatório.

Em relação à idade, $\mathrm{HELKIMO}^{51}$ relatou grande diversificação da prevalência dependendo do sintoma estudado, sendo que pacientes entre 15 e 24 anos apresentavam menor freqüência de sintomas. Já em relação ao gênero, houve a mesma prevalência entre homens e mulheres. $O$ autor concluiu que estes dados em relação a sexo e idade diferem dos artigos prévios e não são representativos para a população em geral.

Em 1975, HANSSON; NILNER ${ }^{46}$ examinaram 1.069 pacientes avaliando a articulação temporomandibular, músculos da mastigação e estruturas associadas. Entre os examinados, um quinto relatou dores de cabeça e um quarto das pessoas reclamaram de sons articulares. Os sons articulares, dor muscular e dor na ATM foram os sinais mais freqüentes no exame clínico, sendo que 30\% da amostra apresentava um ou mais desses sintomas. Os autores finalizaram afirmando que a freqüência dos problemas funcionais é alta e que foi estimado que entre $25 \%$ e $30 \%$ da amostra necessitava de tratamento.

MOLIN et $\mathrm{al}^{84}$, em 1976, analisaram a freqüência dos sintomas de DTM em 253 adultos jovens do gênero masculino, com média de idade de 19 anos, utilizando um questionário, palpação muscular e das ATMs e exame clínico específico. Observaram que pacientes com sintomas clínicos de disfunção tinham maior freqüência de sintomas musculares, ruídos nas ATMs e distúrbios oclusais 
(contatos em não-trabalho) do que aqueles sem sintomatologia. Concluíram que os contatos em não-trabalho foram o único achado oclusal significantemente correlacionado com DTM devido à dor durante o movimento mandibular e sensibilidade à palpação.

Neste mesmo ano, $\mathrm{TIMM}^{120}$ definiu a relação cêntrica como sendo a posição mais aceita pelos côndilos, e uma referência para o ortodontista relacionar adequadamente a oclusão, a articulação temporomandibular e o sistema neuromuscular. $\mathrm{O}$ autor ressaltou ainda que, ao terminar o tratamento ortodôntico, a diferença entre a relação cêntrica e a oclusão cêntrica deve ser de aproximadamente um milímetro, sendo a redução a zero nem prática, nem desejável.

Ao avaliar as características oclusais de 56 pacientes com dor e disfunção mandibular, MOHLIN; KOPP ${ }^{82}$, em 1978, encontraram que as interferências mediotrusivas, mordida cruzada e mordida aberta anterior eram mais comuns que em estudos epidemiológicos. Não houve correlação entre qualquer interferência e o índice de disfunção, assim como o grau de severidade.

Em 1979, WIGDOROWICZ - MAKOWEROWA et al. ${ }^{125}$ realizaram um estudo epidemiológico sobre a prevalência e etiologia dos distúrbios do sistema mastigatório. Cinco populações de diferentes idades e ocupações receberam exame clínico e análise psicológica subjetiva. $O$ aumento da tensão psicoemocional, má oclusão e fatores iatrogênicos foram avaliados como fatores etiológicos. Os autores concluíram que tais distúrbios são causados por fatores locais que 
interferem com a oclusão normal e também pelo aumento da tensão psicoemocional. Afirmaram ainda, que fatores traumáticos como bruxismo e má oclusão aumentam a freqüência de disfunção da ATM, independente da idade ou ambiente, e que os fatores ambientais e condições de vida exercem importante papel na freqüência dos distúrbios, relatando que o estresse mental e a responsabilidade no trabalho são importantes.

SOLERG; WOO; HOUSTON ${ }^{118}$, em 1979, com a finalidade de estabelecer a prevalência de sinais e sintomas de DTM, avaliaram 739 pacientes adultos jovens, com aplicação de um questionário e exame clínico. Os autores observaram que os sinais subclínicos de disfunção são comuns (76\%) em adultos jovens. Não houve diferença estatística significante entre os sexos com relação aos sintomas, contudo, as mulheres apresentaram maior prevalência de sinais. Relataram ainda, que os deslizes de $\mathrm{RC}$ para MIH podem estar associados aos sinais de disfunção.

HAHN $^{44}$ (1979) propôs uma pesquisa em vários países com o objetivo de se observar a influência dos fatores psicológicos na Disfunção Temporomandibular, visto que pacientes jovens e adultos com até 30 anos, raramente apresentam perdas dentais extensas para o comprometimento da ATM. O autor utilizou dois questionários para a determinação do perfil psicológico. O primeiro informava a respeito da condição dentária, condição familiar, tipo de educação, entre outros. 0 segundo era um questionário preparado originalmente para os jogos olímpicos de Munique, a respeito da personalidade. Como conclusão 
relatou que apesar da influência de causas dentais como o encurtamento dos arcos, mordida profunda e interferências oclusais, o elemento psicossomático se sobrepõe em muitos casos.

Com o intuito de avaliar a função da ATM e a oclusão funcional, SADOWSKY; BEGOLE ${ }^{107}$ realizaram um estudo, em 1980, utilizando 75 pacientes entre 25 e 55 anos de idade. Os mesmos receberam tratamento ortodôntico com aparelho fixo por, pelo menos 10 a 35 anos previamente, durante a adolescência. A avaliação realizou-se por meio de um questionário e um detalhado exame clínico. Os resultados foram comparados aos de um grupo controle de adultos com má oclusão, não tratados ortodonticamente. A prevalência de sinais e sintomas de DTM e de contatos oclusais não funcionais foi similar entre os dois grupos. A prevalência de deslocamento mandibular entre $\mathrm{RC}$ e $\mathrm{MIH}$ foi evidente em ambos os grupos e significantemente maior no grupo controle.

A relação entre má oclusão, sintomas de Disfunção Temporomandibular e interferências oclusais foi estudada em 1980, por MOHLIN; INGERVALL; THILANDER ${ }^{83}$, que examinaram 389 pacientes do gênero masculino de 21 a 54 anos de idade. A má oclusão Classe III, mordida cruzada anterior, apinhamento maxilar e a mordida aberta anterior apresentaram uma correlação positiva aos sintomas de Disfunção Temporomandibular e às interferências oclusais. Concluíram que a etiologia da DTM é multifatorial, não sendo possível predizer o risco desta em um indivíduo com má oclusão. 
Em 1981, OKESON ${ }^{87}$ afirmou que o tratamento das patologias oclusais associadas a dores faciais representam um problema complexo. A associação entre as interferências oclusais e o estresse psicológico resulta em atividades parafuncionais. $O$ autor relatou que o mais importante pré-requisito para a escolha do tratamento é o conhecimento da etiologia do problema, afirmando que a precisa determinação da atividade parafuncional, para cada paciente, depende de mais pesquisas nesta área.

Ao examinar pacientes com contatos em lado de nãotrabalho, sem sinais e sintomas de Disfunção Temporomandibular, INGERVALL; CARLSSON ${ }^{56}$ (1982) avaliaram a atividade muscular, comparando com um grupo controle. O estudo não demonstrou influência das interferências oclusais nos músculos analisados, e estas não representam um obstáculo ao funcionamento normal dos músculos mastigatórios, ou ainda que os pacientes estavam bem adaptados à situação oclusal e concluíram que o sistema mastigatório apresenta uma capacidade adaptativa.

Em uma revisão das teorias da etiologia da síndrome dor-disfunção miofascial, $\operatorname{CLARKE}^{17}$, em 1982, examinou, especificamente, a importância da oclusão. Realizou considerações biológicas e observações clínicas e terapêuticas demonstrando que a oclusão não está envolvida na etiologia do bruxismo ou da disfunção e que o efeito placebo pode ser a razão para o sucesso da terapia oclusal. 
MOHLIN ${ }^{81}$, em 1983, relacionou a má oclusão à prevalência de Disfunção Temporomandibular num grupo de 272 mulheres na Suécia, que foram examinadas clinicamente e/ou responderam a um questionário. Os resultados demonstraram uma correlação entre a severidade da disfunção e a necessidade de tratamento ortodôntico e entre esta e a sensibilidade à palpação muscular. O autor concluiu que a etiologia da disfunção é, de forma evidente, multifatorial.

NILNER $^{85}$ (1983) realizou uma pesquisa entre jovens de 7 a 14 anos de idade, relacionando a presença de hábitos parafuncionais e distúrbios funcionais do sistema estomatognático. Não observou diferença entre os pacientes submetidos ao tratamento ortodôntico e os demais. A autora concluiu que existem relações entre dores de cabeça e sensibilidade à palpação na ATM e músculos circundantes, assim como, entre hábitos parafuncionais e interferência na posição de relação cêntrica.

NILNER ${ }^{86}$, ainda em 1983, pesquisou e relacionou a presença de hábitos parafucionais aos distúrbios funcionais do sistema estomatognático em 309 jovens de 15 a 18 anos, utilizando entrevista e exame clínico. Observou a correlação entre interferências oclusais em relação cêntrica e a presença de estalidos articulares. As interferências oclusais também apresentaram-se relacionadas com a sensibilidade à palpação muscular e articular e a sobremordida profunda relacionou-se ao apertamento e desgaste dentário na região anterior. 
Em 1984, MAGNUSSON; ENBON ${ }^{73}$ avaliaram a reação à introdução de interferências no lado de não-trabalho em relação à Disfunção Temporomandibular, em um estudo tipo duplo-cego. Cada grupo continha 12 jovens do gênero feminino, onde um grupo recebeu a introdução de um contato, enquanto no outro tal condição foi apenas simulada. Após duas semanas, o sintoma mais comum foi a dor de cabeça e o sinal mais freqüente foi a sensibilidade à palpação muscular, porém presentes em ambos os grupos. Os autores concluíram que não existe uma simples relação entre a interferência oclusal e a DTM, e que a reação individual aos fatores locais para se criar a disfunção é mais importante, sendo que a DCM poderá se desenvolver sem a existência de interferências oclusais.

DROUKAS; LINDÉE; CARLSSON²7, também em 1984, avaliaram o relacionamento entre os sinais e sintomas das disfunções mandibulares e os fatores oclusais em 48 estudantes de odontologia. Os alunos foram submetidos a um exame clínico e responderam um questionário, de acordo com o índice de HELKIMO ${ }^{48}$. O exame clínico constou de registros das posições cêntrica e excêntrica da mandíbula de acordo com critérios específicos para o registro de uma "oclusão ideal", interferências oclusais e atrição dentária. A freqüência dos sinais e sintomas, embora sempre de uma forma moderada, foi significante. As condições oclusais apresentaram-se extremamente variadas e não mostraram qualquer relação com os sinais e sintomas de Disfunção Temporomandibular. 
SADOWSKY; POLSON ${ }^{108}$, em 1984, realizaram dois estudos longitudinais a fim de investigar as Disfunções Temporomandibulares e a oclusão funcional após o tratamento ortodôntico. Um, em Illinois, utilizando 96 pacientes que receberam tratamento ortodôntico há pelo menos dez anos previamente ao estudo, sendo $66 \%$ deles Classe II e 34\% Classe I. O outro em Eastman, formado por 111 pacientes, sendo 64\% Classe I, 30\% Classe II e 6\% Classe III. Os dois grupos receberam tratamento ortodôntico com aparelho fixo, sendo que $30 \%$ do grupo de Illinois e $36 \%$ de Eastman foram submetidos a extrações como parte da terapia ortodôntica. Os grupos utilizados como controle eram formados de 103 pacientes de Illinois e 111 de Eastman, adultos com má oclusão, não submetidos a tratamento ortodôntico. Quanto à oclusão funcional, verificou-se uma alta incidência, em todos os grupos, de contatos em lado de nãotrabalho e de contatos posteriores durante o movimento protrusivo, não havendo diferença estatística entre eles. Os achados encontrados nos dois grupos foram similares e sugeriram que o tratamento ortodôntico realizado durante a adolescência geralmente não aumenta nem diminui o risco de desenvolver DTM futuramente.

Em 1985, DROUKAS; LINDÉE; CARLSSON ${ }^{28}$ realizaram exames com a finalidade de avaliar alterações do sistema mastigatório, analisando 50 pacientes com a idade entre 16 e 40 anos, com dentição natural e prótese fixa. Os pacientes foram examinados clinicamente em relação à severidade dos sintomas e à condição oclusal (contatos na posição cêntrica, atrição dentária e interferências oclusais) e responderam a um questionário. Concluíram que a oclusão 
apresentou uma grande variação nos pacientes analisados, porém não mostrou relações significantes com os sinais e sintomas da DTM, assumindo que a função ainda permanece obscura.

Com o objetivo de avaliar a influência da função em grupo, desoclusão pelo canino, interferência no lado de trabalho e interferências no lado de não-trabalho, na atividade eletromiográfica dos músculos elevadores da mandíbula, BELSER; HANNAM ${ }^{11}$, em 1985, examinaram 12 pacientes. Os dados foram coletados durante atividades funcionais e hábitos parafuncionais, ocorrendo uma diminuição da atividade muscular quando foi introduzido um guia canino onde originalmente havia função em grupo. A introdução de interferência do lado de não-trabalho alterou a atividade do músculo temporal numa condição de apertamento lateral. Como conclusão do trabalho os autores sugerem que uma condição de desoclusão pelo canino não altera a atividade muscular em atividades funcionais, porém reduzem-na durante apertamento parafuncional.

$\mathrm{BUSH}^{16}$, em 1985, procurou evidenciar alguma relação entre a sensibilidade dos músculos mastigatórios e da ATM, a vários tipos de contatos oclusais, em 298 estudantes de odontologia, sendo 242 do gênero masculino e 56, do feminino, com idade média de 24 anos. A avaliação da amostra foi realizada por palpação muscular e da ATM, exame clínico e dos modelos de estudo montados em articulador semi-ajustável. Não se verificou correlação entre os sintomas de DTM e as más oclusões Classes I, II e III e nem entre qualquer tipo específico de contato oclusal, com a sensibilidade à palpação das estruturas 
consideradas. Verificou ainda, que os estudantes com relação de Classe I, sem sensibilidade à palpação, apresentaram maiores deslizes entre $\mathrm{RC}$ e $\mathrm{MIH}$.

LIEBERMAN et al $^{66}$ (1985) analisaram 369 estudantes israelenses entre 10 e 18 anos de idade, relacionando certas características morfológicas da má oclusão e a presença de três sinais cardinais de Disfunção Temporomandibular (sons articulares, sensibilidade da ATM à palpação e sensibilidade muscular). O tratamento ortodôntico prévio e o desgaste oclusal foram introduzidos na análise estatística como duas variáveis independentes. Os autores concluíram que o desgaste oclusal e a sobremordida excessiva foram os únicos fatores que aumentaram significativamente a presença de disfunção.

Em 1986, MAGNUSSON; EGERMARK; CARLSSON ${ }^{75}$ realizaram um estudo longitudinal dos sinais e sintomas de disfunções mandibulares em 135 adolescentes. Os pacientes foram examinados aos 15 anos e posteriormente aos 20. Os autores utilizaram o índice de HELKIMO ${ }^{48}$ e obtiveram como resultado um aumento na ocorrência dos sintomas subjetivos, porém o índice de disfunção clínico não se mostrou alterado com o aumento da idade da amostra. Relataram ainda, que em ambas as épocas, os ruídos articulares foram os achados mais freqüentes, enquanto aos 20 anos houve aumento nos hábitos parafuncionais. 
FORSSEL; KIRVESKARI; KANGASNIEMI ${ }^{39}$, em 1986, avaliaram o efeito do ajuste oclusal e do tratamento placebo (simulação do ajuste) em um grupo de 96 pacientes com dor de cabeça e com outros sinais e sintomas de DCM. Os pacientes que receberam o tratamento foram reavaliados depois de oito meses e o grupo com simulação de ajuste, após quatro meses, em um estudo do tipo duplocego. O tratamento placebo e o ajuste oclusal foram igualmente efetivos no alívio de sintomas de DCM, mas houve uma redução maior dos sinais no grupo de tratamento oclusal.

No ano seguinte, EGERMARK; CARLSSON; MAGNUSSON $^{31}$ realizaram um estudo longitudinal verificando a influência de fatores oclusais nas disfunções mandibulares em jovens de 7, 11 e 15 anos de idade. Os resultados demonstraram que os sinais e sintomas aumentaram levemente em freqüência e severidade e que os sons articulares apresentaram-se relacionados ao deslize de posição de $\mathrm{RC}$ para a de $\mathrm{MIH}$. Os autores concluíram que não houve forte correlação entre as interferências oclusais e os sintomas, confirmando a natureza heterogênea e multifatorial dos distúrbios do aparelho mastigatório.

WÄNMAN ${ }^{123}$, em 1987, realizou um estudo longitudinal com 285 adolescentes aos 17 e 19 anos de idade, utilizando os índices clínico e anamnésico propostos por $\mathrm{HELKIMO}^{48}$. Os hábitos parafuncionais, apertamento e bruxismo foram bastante comuns. $O$ autor encontrou correlações entre vários sinais e sintomas, sendo que a 
prevalência de sintomas foi significantemente maior para jovens entre 18 e 19 anos.

Em um estudo transversal, RIOLO; BRANDT; TENHAVE ${ }^{104}$, em 1987, analisaram a associação entre as características oclusais e os sinais e sintomas de disfunção da ATM em 1.342 jovens de seis a 17 anos de idade. A amostra foi avaliada quanto à prevalência de (1) tipos específicos de oclusão e (2) sintomas subjetivos e sinais clínicos de disfunção da ATM. Em relação às condições oclusais e os sinais clínicos, os resultados demonstraram que a mudança funcional não estava associada à dor muscular e na ATM, a sobressaliência excessiva ou negativa estava mais associada à dor na ATM. A mordida aberta apresentou associação com a dor muscular e na ATM e os indivíduos mais velhos com mordida de topo ou uma relação molar de Classe II estavam mais relacionados com dor muscular e articular e abertura bucal restrita. Os indivíduos mais velhos com mordida cruzada apresentaram maior prevalência de sons articulares. Quanto à oclusão e os sintomas subjetivos, indicaram que a relação de molar Classe II estava associada aos ruídos articulares nos grupos de 6 a 8 e 15 a 17 anos. Pacientes com sobressaliência negativa foram os que mais relataram ruídos articulares. Os autores concluíram que existem associações estatísticas entre certas características da oclusão e sinais e sintomas da ATM e estas são maiores nos grupos mais velhos.

PULLINGER; SELIGMAN; SOLBERG ${ }^{95}$, em 1988, associaram os fatores oclusais à sensibilidade na ATM e à disfunção em 222 estudantes com idade média de 23,9 anos. Os autores concluíram 
que é vaga a influência da oclusão no desenvolvimento das disfunções da ATM e parece que a diferença entre $\mathrm{RC}$ e $\mathrm{MIH}$ demonstra uma função protetora para o sistema, pois a carga é anterior à posição limite posterior.

SELIGMAN; PULLINGER; SOLBERG ${ }^{113}$, ainda em 1988, associaram os fatores oclusais e articulares e os relacionaram à sensibilidade muscular, utilizando mesmo grupo da pesquisa anterior. Os resultados indicaram que os fatores oclusais não se relacionaram com a palpação e a sensibilidade muscular, porém esta, esteve relacionada aos sinais de patologias intracapsulares, como crepitação e estalido.

Com o objetivo de verificar a presença de interferências oclusais em adultos jovens, AGERBERG; SANDSTRÖM ${ }^{3}$, em 1988, examinaram dois grupos distintos com idades de 15 a 22 anos de idade. Os autores observaram o deslize de $\mathrm{RC}$ para $\mathrm{MIH}$ e a presença de contatos no lado de não-trabalho. Os resultados mostraram que aproximadamente $75 \%$ dos indivíduos de ambos os grupos apresentaram interferências oclusais na posição retruída. Em relação ao movimento lateral, a freqüência das interferências aumentou com a amplitude do movimento. Os autores concluíram que, devido ao alto índice de interferências em pessoas com o sistema mastigatório normal, tal fato não representa grande importância na etiologia da Disfunção Temporomandibular. 
DAHL et $\mathrm{al}^{22}$ (1988) compararam os sinais e sintomas de Disfunção Temporomandibular entre 51 pacientes tratados ortodonticamente e 47 não tratados, todos com 19 anos de idade e num período médio de cinco anos após o término do tratamento. Os pesquisadores não encontraram diferenças substanciais entre os dois grupos.

LIVINGSTON $^{69}$, no seu trabalho, em 1988, relatou que os ortodontistas colocam em risco o complexo temporomandibular quando realizam certos procedimentos, como a retração anterior, devido à extração de pré-molares, acreditando que esses procedimentos provocam disfunções na ATM.

GREENE $^{42}$, em 1988, reavaliou a relação entre a ortodontia e a Disfunção Temporomandibular nos seguintes aspectos: 1) A ortodontia representa um risco no desenvolvimento da DTM? 2) O paciente portador de má oclusão com DTM necessita de tratamento ortodôntico para alívio dos sinais e sintomas da DTM? 3) Um tratamento ortodôntico terminado de forma inadequada aumenta o risco de DTM? 4) Qual deve ser a conduta do ortodontista diante de um paciente com sinais e sintomas de DTM antes ou durante o tratamento? $\mathrm{O}$ autor sugere que a relação DTM / ortodontia está envolvida por mitos e baseada em dados subjetivos. Conclui que a DTM é uma disfunção ortopédica médica bastante complexa e o seu diagnóstico depende do conhecimento multidisciplinar do profissional e do seu domínio sobre o sistema estomatognático. 
Ainda em 1988, SELIGMAN; PULLINGER; SOLBERG ${ }^{114}$ avaliaram a atrição dentária em jovens universitários, a partir de modelos de gesso, comparados pela idade, gênero, presença de bruxismo, classificação de Angle, relação intermaxilar e sinais e sintomas de DTM. A atrição não diferiu entre os grupos pela idade, indicando que quando existente, pode ocorrer precocemente, sendo que, pacientes do gênero masculino apresentaram desgastes mais acentuados. Não se observou relação entre a atrição dentária com a presença ou ausência de estalidos e sensibilidade na ATM e sensibilidade nos músculos mastigatórios. Os achados deste estudo sugerem que a atrição dentária causada pelo bruxismo, em uma população não tratada, não está associada aos sinais e sintomas da DTM.

KIRVESKARI; ALANEN; JÄMSA ${ }^{62}$, em 1989, avaliaram a influência de interferências oclusais nos sinais de Disfunções Temporomandibulares. Dados estatísticos não mostraram correlação entre as interferências e os sinais de DTM, com exceção da época do $3^{\circ}$ exame (controle de três anos). Os autores afirmam que é necessário analisar e definir cuidadosamente o conceito de interferência para que se tornem viáveis novas pesquisas, a fim de discuti-las como agentes etiológicos das DCM, pois um programa de estudo inadequado resulta em resultados falso-negativos.

Em 1990, WÄNMAN; AGERBERG ${ }^{124}$ avaliaram alguns fatores oclusais e psicológicos em jovens de 19 anos de idade e os relacionaram como etiológicos de DCM. Os dados foram coletados por 
meio de um questionário e avaliação clínica, incluindo exame da ATM, dos músculos, mobilidade mandibular e oclusão. O número de contatos oclusais em $\mathrm{MIH}$, durante ligeira pressão foi o fator oclusal mais diretamente relacionado ao número de sinais e sintomas de DCM. O risco de DCM foi três vezes maior no grupo com poucos contatos em $\mathrm{MIH}$ e entre 3,4 a 8,5 vezes no grupo que se considerou tenso.

JANSON; MARTINS ${ }^{57}$ (1990) avaliaram algumas características funcionais da oclusão, presentes de seis meses a um ano após o término do tratamento ortodôntico e analisaram os efeitos do ajuste oclusal sobre as variáveis estudadas. A amostra continha 20 pacientes, sendo 11 do gênero masculino e nove, do feminino, com idade média de 14 anos e 10 meses. Os autores observaram a ausência de coincidência entre as posições de $\mathrm{RC}$ e $\mathrm{MIH}$ em $85 \%$ dos pacientes, presença de guia anterior em $90 \%$ e excursão em lateralidade em 50\% da amostra. Observaram ainda uma alta incidência de interferências oclusais durante os movimentos funcionais, e presença de DTM em 10\% dos pacientes estudados. Finalmente, verificaram que o ajuste oclusal permitiu a obtenção da oclusão de relação cêntrica e o aumento do número de contatos nesta posição, a melhora do padrão de desoclusão, a eliminação das interferências durante os movimentos funcionais e a remissão dos sintomas nos pacientes com Disfunção Temporomandibular. Entretanto este procedimento não permitiu o estabelecimento imediato do guia anterior, quando não estabelecida por meio do tratamento ortodôntico. 
HEIKINHEIMO et al. ${ }^{47}$, em 1990, avaliaram, em um estudo longitudinal, a presença de interferências oclusais e sinais de Disfunção Temporomandibular, em 167 pacientes entre 12 e 15 anos, avaliando sua importância no diagnóstico ortodôntico. Os sintomas de DTM são comuns, mas inconsistentes no diagnóstico para o tratamento ortodôntico. A abertura bucal aumentou com a idade, bem como o número de interferências oclusais durante os três anos de estudo. Diante destes resultados, os autores concluíram que nenhum sinal ou sintoma de DTM, ou uma combinação deles pode ser utilizada como determinante para o tratamento ortodôntico.

No mesmo ano, EGERMARK et al. ${ }^{33}$ examinaram um grupo de crianças e adolescentes com 7, 11 e 15 anos, verificando a má oclusão morfológica e sinais e sintomas de DTM. Verificaram que as más oclusões como a mordida aberta anterior, a mordida cruzada, as relações de Classes II e III de Angle podem ser um fator de risco no desenvolvimento da DTM. Alguns destes indivíduos foram tratados, porém quando comparados aos não tratados, não apresentaram diferenças quanto a sinais e sintomas de DTM e interferências oclusais.

Em uma revisão sobre a influência da oclusão nos sintomas temporomandibulares, LIPP68, em 1990, relatou a falta de evidências científicas que comprovem tal interferência e que o sucesso de tratamentos placebos constitui uma delas. O autor concluiu que a capacidade de remodelação da articulação temporomandibular demonstra que a mesma pode acomodar-se e adaptar-se às várias condições oclusais. 
Com o objetivo de investigar se pacientes tratados ortodonticamente apresentavam um funcionamento do sistema mastigatório semelhante aos pacientes não tratados, KEB; BAKOPULOS; WITT ${ }^{60}$, em 1991, avaliaram 54 pacientes tratados ortodonticamente e 52, não tratados, com idades de 20 a 30 anos. Os autores realizaram avaliação clínica (palpação muscular e da ATM e presença de sons articulares e dor durante o movimento mandibular), avaliação oclusal (número e natureza dos contatos em RC, MIH, guia anterior e lateral) e avaliação instrumental (posição e movimento condilar). Os resultados foram transferidos para um programa de computador que determinava automaticamente os índices de $\mathrm{HELKIMO}^{48}$. Os achados deste estudo não indicaram o tratamento ortodôntico como causa das desordens do sistema estomatognático, pois os pacientes tratados apresentaram a oclusão e o funcionamento da ATM melhor que o grupo controle. Diante destes resultados os autores concluíram que os sintomas de Disfunção Temporomandibular podem ocorrer em casos individuais, mas não parece haver relação entre os distúrbios funcionais e o tratamento ortodôntico bem realizado.

Em 1991, SELIGMAN; PULLINGER ${ }^{111}$ publicaram uma revisão a respeito da influência das relações oclusais com a Disfunção Temporomandibular. Concluíram que o overbite e o overjet não exercem um papel importante das disfunções não artróticas e que a mordida cruzada não parece provocar sintomas na ATM.

No mesmo ano, SELIGMAN; PULLINGER ${ }^{112}$ revisaram a influência dos contatos nos lados de trabalho e não-trabalho, grau de 
deslize entre a posição retruída (P.R.) e posição de intercuspidação (P.I.), padrão de guias oclusais, parafunção e atrição dentária, na Disfunção Temporomandibular. Os autores concluíram que os estudos falham em demonstrar relação direta entre interferências oclusais e DTM e que o deslize entre a P.R. e a P.I. pode ser um fator de risco para certos pacientes. Afirmam também que os padrões das guias oclusais influenciam os níveis de atividade muscular, mas não parecem provocar DTM. Em relação à parafunção e atrição dentária severa, parecem estar mais presentes em homens.

PULLINGER; SELIGMAN ${ }^{92}$ (1991) estudaram o overjet e o overbite como variáveis em relação a grupos portadores de Disfunção Temporomandibular, comparando-os a um grupo controle livre de sintomas. Os pacientes foram divididos em grupo controle (sem sinais e sintomas de DTM), grupo com deslocamento de disco sem redução, grupo com deslocamento de disco com redução, grupo com osteoartrose articular sem história de degeneração da ATM, grupo com osteoartrose e história degenerativa e um grupo apenas com mialgia. Os resultados demonstraram que a mordida aberta ocorreu apenas nos grupos com osteoartrose e em alguns casos com mialgia, mas foi ausente no grupo controle. O overbite não foi comum em nenhum dos grupos e o overjet, observado com maior freqüência no grupo com osteoartrose, mas não se caracterizou como um grupo determinante no diagnóstico de DTM. Com base nos resultados, concluíram que a mordida aberta está associada à osteoartrose e que o overbite, o overjet e mesmo a mordida aberta não podem ser consideradas isoladamente como causa da DTM. Os valores de 1 a $4 \mathrm{~mm}$ para overbite e 1 a $3 \mathrm{~mm}$ 
para overjet são considerados como objetivo final no tratamento ortodôntico, contudo, não se pode afirmar que o aumento desses valores em pacientes tratados ortodonticamente possa ser considerado responsável pelo aparecimento de Disfunção Temporomandibular.

KREMNAK et $\mathrm{al}^{64}$ (1992) analisaram o tratamento ortodôntico como um fator de risco para a Disfunção Temporomandibular. Em um estudo longitudinal os autores avaliaram 109 pacientes, antes e em intervalos durante e após o tratamento ortodôntico. Os autores concluíram que, segundo a metodologia utilizada, o tratamento ortodôntico não representa um importante fator etiológico da Disfunção Temporomandibular.

EGERMARK; THILANDER ${ }^{30}$, em 1992 reexaminaram um grupo de crianças e adolescentes com sinais e sintomas de Disfunção Temporomandibular e avaliaram as diferenças entre os pacientes que receberam tratamento ortodôntico e os não tratados. Foram avaliadas nesta pesquisa 402 pacientes divididos, por idade, em três grupos ( $7,11,15$ anos), que participaram de um estudo prévio e foram reexaminados dez anos após o estudo inicial. Os pacientes responderam a um questionário e foram examinados clinicamente. Os resultados demonstraram que os pacientes tratados ortodonticamente apresentaram menor prevalência de sintomas e menor índice clínico de disfunção. 
Com a finalidade de identificar pacientes ortodônticos com Disfunção Temporomandibular, HANS et al. ${ }^{45}$, em 1992, realizaram exame clínico, ressonância magnética e aplicação de um questionário em 51 pacientes. Os autores concluíram que a história e o exame clínico são os testes diagnósticos de escolha para pacientes ortodônticos porque juntos, eles são um teste sensitivo para todas as formas de disfunções temporomandibulares e que a imagem por ressonância magnética, enquanto específica para desordens de interferência de disco da ATM, não identifica pacientes com DTM em potencial resultantes de outras causas.

SADOWSKY ${ }^{106}$, em 1992, revisou a literatura sobre o risco do tratamento ortodôntico no desenvolvimento da Disfunção Temporomandibular. Concluiu que o tratamento ortodôntico realizado em crianças e adolescentes não representa um risco para a DTM, pois sua etiologia é multifatorial e que a mecanoterapia ortodôntica produz mudanças graduais em um ambiente que é, em geral, totalmente adaptativo.

Com o objetivo de determinar a incidência de dor e disfunção em pacientes ortodônticos, RENDELL; NORTON; GAY ${ }^{97}$, em 1992, avaliaram 451 pacientes sem sinais e sintomas de Disfunção Temporomandibular no início do tratamento e $11 \mathrm{com}$ sintomatologia. Os pacientes foram avaliados por uma versão modificada dos índices de disfunção e anamnésico de $\mathrm{HELKIMO}^{48}$. Aqueles que não apresentaram disfunção no início, não a desenvolveram no decorrer do tratamento e os outros 11 com disfunção não apresentaram alterações consistentes 
neste período. Baseados nestes resultados não foi possível estabelecer uma relação entre a disfunção e o tratamento ortodôntico.

OLSSON; LINDQVIST ${ }^{89}$, em 1992, avaliaram 245 pacientes tratados ortodonticamente e 245, como controle, segundo idade, sexo e necessidade de tratamento (graduada em uma escala progressiva de acordo com um índice proposto pela Swedish Board of Health and Welfare), utilizando os índices anamnésico e clínico de $\mathrm{HELKIMO}^{48}$. Os autores observaram que no grupo de pacientes, a freqüência dos sinais e sintomas de DTM foi mais alta nos indivíduos mais velhos e do gênero feminino, e concluíram que os pacientes ortodônticos parecem apresentar maior risco de DTM.

Ainda em 1992, FONSÊCA ${ }^{35}$ propôs-se a verificar a confiabilidade de um questionário anamnésico, comparado ao índice clínico modificado de $\mathrm{HELKIMO}^{48}$, avaliando 120 pacientes de DTM. Obteve um índice de confiabilidade de 95\% devido à alta correlação entre respostas do questionário e achados clínicos. Sugeriu a adoção desse índice anamnésico devido as suas vantagens de menor custo e rapidez, sendo indicado para pesquisas epidemiológicas, em serviços públicos.

Com a finalidade de comparar os sinais e sintomas de DTM, WADHWA; UTREJA; TEWARI ${ }^{122}$, em 1993, avaliaram, de acordo com os princípios de $\mathrm{HELKIMO}^{48}$, três grupos de jovens: 30 com oclusão normal, 41 com má oclusão não tratada e 31 pacientes tratados ortodonticamente. Os resultados demonstraram que o grupo com 
oclusão normal apresentou o maior número de jovens sem disfunção, mas esta diferença não foi estatisticamente significante. O único achado significante foi a diferença do índice clínico de disfunção entre os grupos com oclusão normal e com má oclusão não tratada. Concluíram que a ausência de diferenças substanciais entre os três grupos, indica que o papel do tratamento ortodôntico como preventivo ou precipitador das DTM continua questionável, necessitando de maior atenção para o fator estresse.

KEELING, et al. ${ }^{61}$ avaliaram, em 1994, o relacionamento entre os sons articulares (estalido e crepitação) e as características esqueléticas e dentárias em 3.428 estudantes, com idade de 6 a 12 anos, sem história de tratamento ortodôntico. Os examinadores observaram sons articulares em 10\% da amostra e não encontraram associação entre a prevalência dos sons articulares com a idade, sexo, raça e relação molar e concluíram que pacientes com grande abertura bucal, apinhamento anterior e sobremordida profunda têm um risco aumentado de apresentarem estalido ou crepitação na ATM.

Um estudo sobre os sinais clínicos da Disfunção Temporomandibular foi realizado por MAGNUSSON; CARLSSON, EGERMARK $^{74}$, em 1994, em uma amostra, composta de 84 pacientes, acompanhados longitudinalmente dos 15 aos 25 anos de idade. Não observaram diferenças em nenhum sinal clínico e nenhum paciente apresentou sinais severos de disfunção. Encontraram ainda um aumento de interferências em RC em 74\% e em lado de não-trabalho em $32 \%$ dos casos. 
VLACHOS $^{121}$, em 1995, analisou os objetivos do tratamento ortodôntico em duas partes: oclusão estática e oclusão funcional. Avaliou ainda o tratamento como causa e cura da Disfunção Temporomandibular. O autor evidenciou que o tratamento ortodôntico não representa um fator de risco para a DTM, como também não foi comprovada sua participação enquanto causa, prevenção ou cura.

Em 1995, EGERMARK; RÖNNERMAN ${ }^{29}$ examinaram um grupo de 50 pacientes, tratados ortodonticamente, analisando sinais e sintomas de DTM, presença de dores de cabeça, bruxismo e interferências oclusais, utilizando questionários e exame clínico, antes, durante e imediatamente após o tratamento. Utilizaram como grupo controle comparativo, 135 pacientes. Concluíram não existir diferenças entre sinais e sintomas de DTM, dores de cabeça e bruxismo nos pacientes tratados ortodonticamente, com e sem extrações. Verificaram que alguns pacientes apresentavam sinais de disfunção e interferências no lado de não-trabalho e que durante a fase ativa de tratamento e de contenção eram bastante reduzidas. Os pacientes apresentaram menos sinais e sintomas de DTM durante, do que antes do tratamento.

Em uma revisão de literatura MCNAMARA JÚNIOR; SELIGMAN; OKESON ${ }^{76}$, em 1995, analisaram a interação das oclusões morfológica e funcional com a Disfunção Temporomandibular, avaliando os seguintes fatores: mordida aberta anterior esquelética, overjet maior que $6 \mathrm{~mm}$, discrepância entre $\mathrm{RC}$ e $\mathrm{MIH}$ maior que $4 \mathrm{~mm}$, mordida cruzada posterior unilateral e perda de mais de cinco dentes posteriores. 
Os autores concluíram que os três primeiros fatores estão freqüentemente associados a artropatias da ATM e podem ser 0 resultado de alterações ósseas e ligamentosas dentro da ATM. Analisaram também a relação tratamento ortodôntico e Disfunção Temporomandibular, concluindo: 1) sinais e sintomas de DTM ocorrem em indivíduos normais; 2) sinais e sintomas da DTM aparecem bastante na adolescência, o que significa que não existe relação com o tratamento ortodôntico; 3) o tratamento ortodôntico não causa nem previne a DTM na idade adulta; 4) a extração dentária como parte do tratamento ortodôntico não aumenta o risco de DTM; 5) não existe diferença no tipo de mecânica ortodôntica que possa provocar DTM; 6) embora uma oclusão estável seja a meta do tratamento ortodôntico, quando não conseguida, não é o gatilho para sinais ou sintomas da DTM; 7) o tratamento ortodôntico não é preventivo para DTM e 8) quando sinais e sintomas de DTM estão presentes, uma simples terapêutica de tratamento pode aliviá-los.

Analisando 36 pacientes tratados ortodonticamente pela técnica "edgewise" e 30 pacientes sem tratamento, HWANG; BEHRENTS $^{55}$, em 1996, estudaram a relação entre tratamento ortodôntico e a discrepância determinada pelos movimentos mandibulares. Foram obtidos modelos de estudos, montados em articulador semi-ajustável, em posição de RC, que permitia também uma análise da $\mathrm{MIH}$, pela comparação entre ambas. Observaram um contato prematuro em $86,7 \%$ dos pacientes não tratados e $58,3 \%$ nos tratados. Analisando os pacientes com mais de dois contatos prematuro, verificaram que os tratados apresentaram um percentual de $41,6 \%$ e os 
pacientes do grupo controle não apresentaram mais de dois contatos. Observaram que os contatos estavam associados à inclinação vestibular da cúspide palatina dos molares superiores. Encontraram um maior número de contatos nos molares para ambos os grupos e que no grupo tratado com extração de primeiros pré-molares, o contato passava para os segundos pré-molares. Concluíram com as observações encontradas que o tratamento ortodôntico não resulta em um aumento na discrepância cêntrica.

CONTI et $\mathrm{al}^{19}$ (1996) avaliaram a prevalência e a necessidade de tratamento de DTM em estudantes de cursos préuniversitários da cidade de Bauru-SP, analisando os fatores psicológicos e oclusais como agentes etiológicos. Avaliaram 310 estudantes por questionário anamnésico, exame oclusal, palpação muscular e das ATMs. A análise estatística mostrou uma relação entre a presença e o grau de DTM e os aspectos oclusais, psicológicos e sensibilidade à palpação. Concluíram que: a) a prevalência de DTM foi de 49,35\% leve, $10,32 \%$ moderada e 0,97\% severa; b) as mulheres apresentaram uma prevalência de DTM maior que os homens; c) não houve diferença estatística significante entre os grupos estudados; d) a oclusão não apresentou participação na severidade da DTM; e e) a palpação muscular mostrou-se efetiva para se detectar a DTM. Apesar da prevalência ser relativamente alta, a necessidade de tratamento (DTM moderada e severa) para o grupo estudado foi de $11,21 \%$.

No mesmo ano, DONEGAN; CHRISTENSEN; MC KAY ${ }^{26}$ examinaram a presença e a ausência de guia canino, comparando-as 
com sons articulares da ATM em 46 pacientes com Disfunção Temporomandibular e 46 como grupo controle sem sinais e sintomas de disfunção. Os autores observaram uma prevalência baixa de guia em ambos os grupos (22\% em pacientes e $30 \%$ no grupo controle) e não encontraram relação entre a presença de sons articulares e o guia canino. Concluíram que não é possível distinguir o potencial de pacientes ou não pacientes de DTM, com base no guia canino.

Pelas respostas de um questionário anamnésico e com o exame clínico em adolescentes do gênero feminino com oclusão normal e portadoras de má oclusão Classe II, em 1997, HENRIKSSON; EKBERG; NILNER ${ }^{53}$ estudaram a função mandibular, as dores de cabeça e os sinais e sintomas de DTM. Observaram que os sinais e sintomas de DTM foram mais comuns nas jovens com má oclusão e que - grupo com oclusão normal tinha um maior número de contatos dentários em $\mathrm{MIH}$. A presença de overjet maior ou igual a $6 \mathrm{~mm}$, mordida aberta anterior, poucos contatos oclusais, desvio de $\mathrm{RC}$ para $\mathrm{MIH}$, apinhamento e interferências do lado de não-trabalho, estavam sempre mais presentes no grupo de Classe II, concluindo que pacientes com oclusão normal tem menor possibilidade de apresentarem DTM.

BOER; STEENKS ${ }^{13}$ (1997) avaliaram a relação entre o tratamento ortodôntico precoce da mordida cruzada posterior unilateral funcional e o funcionamento da ATM. Foram analisadas 44 crianças, com idade média de cinco anos, avaliadas no início do tratamento, final e oito anos após o período de contenção. Os pacientes foram analisados quanto ao número de contatos em $\mathrm{RC}$ e $\mathrm{MIH}$, diferença entre 
RC e $\mathrm{MIH}$, palpação dos músculos masseter e temporal, análise dos movimentos mandibulares e ATM. Foram obtidos modelos de estudo em todas as fases estudadas. Após a análise dos resultados, concluíram que $\mathrm{o}$ tratamento precoce cria condições de crescimento $\mathrm{e}$ desenvolvimento normais, contudo, não se pode afirmar que este tipo de tratamento é preventivo à Disfunção Temporomandibular.

HENRIKSON; EKBERG; NILNER ${ }^{54}$, em 1998, estudaram um grupo de 183 pacientes jovens do gênero feminino entre 11 e 15 anos, sendo que 60 apresentavam oclusão normal e 123 eram portadoras de má oclusão Classe II, divididos em grupos que receberiam tratamento ortodôntico (grupo II, 65 pacientes) e que permaneceriam sem tratamento (grupo III, 58 pacientes). Todas as pacientes passaram por exame anamnésico e de eficiência mastigatória, com o objetivo de comparação da eficiência na mastigação entre o grupo com oclusão normal e grupo com portadoras de má oclusão Classe II, verificando os fatores oclusais e sintomas de Disfunção Temporomandibular como relevantes na mastigação. Os resultados demonstraram que o grupo I (oclusão normal) apresentou melhor eficiência mastigatória e menos sinais e sintomas de Disfunção Temporomandibular e as pacientes com poucos contatos oclusais e overbite acentuada apresentavam uma reduzida eficiência mastigatória. Concluíram que a eficiência mastigatória depende da oclusão e que pacientes portadores de DTM podem influenciar também numa boa mastigação. 
Ainda em 1998, LUTHER; MORTH ${ }^{72}$, em uma revisão de literatura, estudaram a oclusão funcional (normal), a má oclusão e a Disfunção Temporomandibular, com o objetivo de esclarecer algumas dúvidas: 1) O tratamento ortodôntico deve terminar com uma oclusão funcional?; 2) O tratamento ortodôntico, quando terminado em oclusão funcional pode ser considerado como êxito? E se não for conseguido?; 3) A oclusão funcional quando conseguida, é estável? Concluíram ser necessário outros estudos, com metodologia mais específica para poder relacionar má oclusão e DTM. Embora estes fatores possam estar relacionados entre si, não implica uma relação de causa e efeito, e que a má oclusão e o tratamento ortodôntico não podem ser relatados como causa ou cura da DTM.

Em 1999, FELDMANN; LUNDSTRÖM; PECK ${ }^{34}$ utilizando uma amostra de 47 pacientes com overbite acentuada portadores de má oclusão Classe II, divisão 1, sem tratamento ortodôntico, analisaram as alterações oclusais neles encontradas, em modelos e telerradiografias. Este grupo, formado por 32 pacientes do gênero masculino e 15 do gênero feminino, foram reexaminados após um tempo médio de 11,5 anos. Analisaram e compararam o relacionamento antero-posterior dos caninos, overbite, overjet, apinhamento e espaços interdentais em cada arco. Os resultados demonstraram que após 11,5 anos ocorreu uma diminuição da relação Classe II de molares e caninos, como também do overbite, overjet e espaço nos arcos superiores e inferiores. Estes resultados permitiram concluir que pacientes não tratados de Classe II, divisão1, quando 
crianças, não sofrerão necessariamente de problemas oclusais ao se tornarem adultos.

TEIXEIRA; MARCUCCI; LUZ ${ }^{119}$, em 1999, analisaram a relação de freqüência nas má oclusões dos índices anamnésicos e clínicos de disfunção segundo HELKIMO ${ }^{48}$ (1974), em 110 pacientes, independentemente de sexo, idade e de serem portadores ou não de Disfunção Temporomandibular. Para isto, verificaram sinais e sintomas, níveis de índices de $\mathrm{HELKIMO}^{48}$, classificação de Angle, medidas de overjet e overbite, mordidas cruzadas e número de dentes ausentes. Ao relacionar o índice anamnésico com overjet maior que dois milímetros encontraram sintomas de leve a intenso de disfunção. Afirmaram que houve uma relação estatisticamente significante para índices clínicos de disfunção com a Classe II de Angle e índices anamnésicos com overbite.

Em 1999, KAHN et al. ${ }^{59}$ avaliaram 82 pacientes considerados normais (assintomáticos) e 263 com Disfunção Temporomandibular com um questionário anamnésico, exame clínico e radiográfico agrupando-os em: a) assintomáticos; b) assintomáticos com deslocamento de disco, c) sintomáticos com posicionamento normal de disco e d) sintomáticos com deslocamento de disco. Os resultados demonstraram que a grande maioria dos pacientes analisados apresentava uma relação molar Classe I e que entre os sintomáticos prevalecia uma relação molar Classe II, divisão 1. Outro fato importante analisado foi que os pacientes assintomáticos apresentavam contatos prematuros do lado de não-trabalho, sem desenvolverem sintomas de 
DTM. Concluíram que diferenças de relações oclusais e contatos prematuros encontrados entre os grupos estudados, não podem levar a uma afirmação direta que sejam eles os responsáveis pela Disfunção Temporomandibular.

PULLINGER; SELIGMAN ${ }^{94}$, em 2000, avaliaram o potencial que as variáveis oclusais como discrepância entre $\mathrm{RC}$ e $\mathrm{MIH}$, mordida cruzada posterior, overjet e overbite, desvio de linha média, podem apresentar para diferenciar pacientes com DTM de indivíduos normais assintomáticos, em 381 pacientes do gênero feminino, comparando com um grupo controle de 98 mulheres. Observaram que a oclusão pode ser um cofator na identificação de pacientes com DTM e que algumas variações representam uma conseqüência da disfunção. 
Proposição 


\section{3 - PROPOSIÇÃO}

Como observado na Revisão da Literatura, há grande diversidade de opiniões em relação à etiologia das DTM, sendo os fatores oclusais os mais relatados, por parte dos pesquisadores.

Desta forma, com uma amostra de 200 pacientes portadores de más oclusões Classes I e II, tratados e não tratados ortodonticamente, divididos em quatro grupos, propõe-se determinar:

3.1 - A prevalência de DTM nos diferentes grupos avaliados;

3.2 - A participação dos seguintes aspectos oclusais como causa de DTM:

a) Número de contatos na posição de $\mathrm{MIH}$,

b) Discrepância entre as posições de $\mathrm{RC}$ e $\mathrm{MIH}$,

c) Contatos no lado de não-trabalho,

d) Tipo de guia lateral $\mathrm{e}$

e) Guia anterior;

3.3 - O relacionamento entre a DTM e a oclusão morfológica nos seguintes aspectos:

a) Mordida aberta anterior,

b) Mordida cruzada posterior,

c) Overjet e overbite e 
3.4 - O relacionamento entre a presença de sinais e sintomas de DTM e de:

a) Ajuste oclusal,

b) Presença de facetas de desgate. 


\section{Material e Métodos}




\section{4 - MATERIAL E MÉTODOS}

\section{1 - AMOSTRA}

O objetivo desse estudo foi analisar a prevalência de Disfunções Temporomandibulares em jovens portadores de más oclusões de Classe I e Classe II de Angle. Os pacientes tratados ortodonticamente receberam o mesmo na Faculdade de Odontologia de Bauru, Universidade de São Paulo. A amostra constou de 200 pacientes divididos em quatro grupos, sendo $40 \%$ do gênero masculino e $60 \%$ do feminino.

Grupo I: 50 jovens, entre 9 e 14 anos de idade, com má oclusão de Classe I, não tratados ortodonticamente.

Grupo II: 50 jovens entre 9 e 14 anos de idade, com má oclusão de Classe II, não tratados ortodonticamente.

Grupo III: 50 pacientes, entre 15 e 20 anos de idade, com má oclusão de Classe I, após o tratamento ortodôntico.

Grupo IV: 50 pacientes, entre 15 e 20 anos de idade, com má oclusão de Classe II, após o tratamento ortodôntico. 


\section{2 - HISTÓRIA MÉDICA}

Os pacientes foram inquiridos sobre a ocorrência de problemas de saúde atuais relacionados aos sistemas cardiovascular, digestivo, musculoesqueletal, endócrino, respiratório e neurológico.

\section{3 - APLICAÇÃO DO QUESTIONÁRIO}

Aos pacientes foram solicitados o preenchimento de uma ficha contendo informações pessoais (nome, idade, sexo, endereço, telefone) e questões sobre sintomas relativos às DTM (questionário anamnésico).

Este questionário foi desenvolvido baseado em fichas preexistentes $^{19,35,48}$ e aplicado aos pacientes sem interferência do examinador, de modo que não se criasse uma expectativa, podendo desviar os resultados do exame clínico a ser realizado. Os pacientes responderam 13 perguntas relativas a sintomas, sendo que as primeiras dez, permitiram a obtenção de uma classificação do caso em relação ao grau de disfunção, e as outra três foram analisadas separadamente. Esse questionário foi modificado a partir de trabalhos prévios que demonstraram a eficiência da obtenção de um diagnóstico pela anamnese ${ }^{19}$. 


\section{ANAMNESE}

1. Você sente dificuldade de abrir a boca?

2. Você sente dificuldade de movimentar sua mandíbula para os lados?

3. Você sente desconforto ou dor muscular quando mastiga?

4. Você sente dores de cabeça com freqüência?

5. Você sente dores no pescoço e/ou ombros ?

6. Você sente dores de ouvido ou próximo a ele?

7. Você percebe algum ruído na ATM ?

8. Você considera sua mordida "normal" ?

9. Você usa apenas um lado de sua boca para mastigar?

10. Você sente dores na face ao acordar?

Ainda questões sobre tensão emocional, tratamento ortodôntico e a presença de hábitos deletérios, representadas pelas questões 11, 12 e 13 (observadas nos anexos deste trabalho), foram respondidas pelos indivíduos de toda a amostra. Apertamento dos dentes, bruxismo, onicofagia, entre outros, constituíam os hábitos presentes na ficha de anamnese.

Foram oferecidas as possibilidades das respostas: "sim", "não" ou "às vezes", com exceção das questões 12 e 13. Cada "sim" recebeu o valor 2 , "às vezes" valor 1 e 0 para a resposta "não". As questões 4, 6 e 7 receberam valor 3 quando a resposta "sim" 
correspondia a sintomas bilaterais ou intensos, 2 se unilaterais ou leves, 1 “às vezes" e zero para "não", de acordo com CONTI et al $^{19}, 1996$.

O somatório dos valores obtidos permitiu a classificação da amostra em relação à DTM em:

Valores de 0 a 3: $\quad$ não portador de DTM

Valores de 4 a 8: $\quad$ portador de DTM leve

Valores de 9 a 14: portador de DTM moderada

Valores de 15 a 23: portador de DTM severa

\section{4 - EXAME CLÍNICO}

Os materiais utilizados para o exame clínico foram :

a) papel celofane;

b) fita detectora de contatos (Accu-Film*)

c) pinça de Miller e

d) espelho clínico.

O exame clínico foi realizado por dois examinadores treinados, previamente calibrados, para a obtenção dos dados relacionados com a avaliação da ATM, dos músculos e dos dentes e da oclusão. No que se refere à quantidade de força a ser aplicada, os examinadores foram treinados com a utilização de um algômetro 
(aparelho que mede a sensibilidade à dor, causada por pressão). Esta avaliação foi realizada com os pacientes sentados e relaxados.

\subsection{1 - AVALIAÇÃO DA ATM}

Os movimentos mandibulares foram os primeiros itens analisados. Observou-se o grau de abertura bucal ativa (incluindo o trespasse), lateralidade direita e esquerda e a protrusão.

\subsubsection{1 - Abertura bucal ativa}

O paciente foi solicitado a abrir a boca ao máximo e realizava-se a medição, com uma régua milimetrada, da distância interincisivos superior e inferior, tomando como referência a linha mediana. A este valor somou-se a medida do trespasse vertical.

\subsubsection{2 - Lateralidade e protrusão}

Realizou-se este procedimento marcando, com grafite 0,5mm, a linha média no arco inferior, a partir do arco superior. Em seguida o paciente foi solicitado a movimentar a mandíbula para os lados e com uma régua posicionada no plano horizontal, realizava-se a medida da linha média superior até a linha marcada no arco inferior das excursões máximas.

Solicitando-se ao paciente para realizar o movimento para a frente da mandíbula, mediu-se a protrusão. Para tal usava-se 
uma régua posicionada no plano horizontal, tocando a face vestibular do incisivo central superior, e com o paciente em posição protrusiva, tomava-se a medida até a face vestibular do incisivo central inferior acrescentando-se o trespasse horizontal.

\subsubsection{3 - Análise de ruídos articulares}

Os ruídos articulares (estalido e crepitação) eram observados posicionando-se os dedos indicadores levemente na região correspondente ao pólo lateral do côndilo, à frente do meato acústico externo, enquanto o paciente realizava movimentos de abertura e fechamento mandibular. Durante este exame, a hipermobilidade da articulação temporomandibular era também analisada.

\subsubsection{4 - Palpação da ATM}

A avaliação da presença de sintomatologia dolorosa na ATM foi realizada inicialmente orientando o paciente quanto à diferença entre pressão e desconforto, com a finalidade de não gerar dúvidas durante as respostas. Realizou-se palpação digital bilateral com os dedos indicadores 10 a $20 \mathrm{~mm}$ à frente do conduto auditivo externo, instruindo o paciente a realizar o movimento de abertura e fechamento. Pressionou-se a região delicada e continuamente, com uma carga de aproximadamente 450 a 900 gramas de acordo com AUSTIN; PERTES ${ }^{9}$. Desta forma avaliou-se a ATM com a boca fechada (aspecto lateral) e aberta (aspecto posterior). 


\subsection{2 - EXAME MUSCULAR}

A palpação muscular foi realizada bilateralmente, exercendo pressão firme, porém de maneira suave, com a sensação dolorosa constatada pelo reflexo palpebral e/ou questionamento ao paciente. Procurou-se manter uma pressão constante de aproximadamente 1500 gramas de acordo com CONTI et al ${ }^{19}$ em 1996.

Os músculos palpados foram: temporal (anterior, médio e posterior), masséter superficial (origem, médio e posterior), masséter profundo, digástrico posterior, esternocleidomastoideo e trapézio (superior).

\subsection{3 - AVALIAÇÃO DENTÁRIA E OCLUSAL}

Toda a cavidade bucal foi inspecionada, procurando-se verificar a ausência de dentes, facetas de desgaste, overjet e overbite, relações maxilomandibulares $(\mathrm{RC}$ e $\mathrm{MIH})$, presença e tipo de guias lateral e anterior, interferências no lado de não-trabalho, número de contatos dentários em $\mathrm{MIH}$. A mensuração do overjet e do overbite foi realizada com o auxílio de uma régua milimetrada.

Para averiguar as diferenças das posições maxilomandibulares obteve-se a posição de $\mathrm{RC}$ com a técnica de manipulação unilateral do paciente ${ }^{118}$ e comparou-se à posição de $\mathrm{MIH}$, medindo-se a discrepância vertical entre essas posições. 
Realizou-se a avaliação da presença e do tipo de guia lateral, utilizando uma tira de papel celofane para verificar a presença de interferências no lado de não-trabalho. A presença de guia anterior foi conferida solicitando aos pacientes para protruir a mandíbula até a posição de topo. O número de contatos em $\mathrm{MIH}$ foi obtido interpondo uma folha de Accu-Film entre os dentes enquanto o paciente abria e fechava a boca.

Os tipos de má oclusão foram relacionados classificando a relação sagital em relação de Classes I e II. Consideraram-se ainda a presença das mordidas aberta e cruzada (uni e bilateral).

Avaliou-se ainda, o tipo de aparelho utilizado nos pacientes tratados ortodonticamente, além do aparelho fixo. O tratamento ortodôntico foi analisado também em relação à extração ou não de pré-molares.

O término do tratamento e o tempo de uso de contenção, em meses, foi registrado pelos examinadores, considerando se o paciente se submeteu ao ajuste oclusal após o tratamento ortodôntico. 


\section{5 - ANÁLISE ESTATÍSTICA}

As freqüências das diversas variáveis analisadas foram expressas em percentual.

Para a obtenção dos resultados foram aplicados os testes:

- Teste de Análise de Variância (ANOVA) para dados não paramétricos (Kruskal-Wallis) foi utilizado para análise das diferenças intergrupos do índice de DTM, overjet, overbite e número de contatos oclusais.

- Teste de Correlação de Spearman testou a associação entre o índice de DTM e o overjet e o overbite.

- Teste de qui-quadrado analisou a associação entre o índice de DTM e as demais variáveis oclusais consideradas nesta pesquisa.

A execução dos testes estatísticos foi realizada com o auxílio dos programas de computador Sigmastat ${ }^{*}$ e Systat ${ }^{\star *}$. 
Resultados 


\section{5 - RESULTADOS}

\section{1 - RESULTADOS DESCRITIVOS}

\subsection{1 - DADOS GERAIS E PREVALÊNCIA DE DTM}

Este estudo analisou uma amostra de 200 indivíduos, sendo que 100 deles constituíram os grupos I (Classe I, não tratados) e II (Classe II, não tratados) e apresentaram idade média de 12,4 anos. Outros 100 constituíram os grupos III ( Classe I, tratado) e IV (Classe II, tratado) com idade média de 17,3 e 17,4 respectivamente. A amostra geral era constituída de $40 \%$ de indivíduos do gênero masculino e $60 \%$ do feminino.

Quanto à saúde geral, $72,5 \%$ dos entrevistados, não mostraram problemas sistêmicos.

Os resultados do questionário anamnésico, elaborado com o objetivo de se criar um meio diagnóstico em relação à DTM, encontram-se nas Tabelas 5.1, 5.2, 5.3 e 5.4, divididos pelos grupos de estudo. 
Tabela 5.1 - Freqüência percentual das respostas do questionário anamnésico pelo grupo I (Classe I sem tratamento ortodôntico)

\begin{tabular}{|c|c|c|c|}
\hline Questão & SIM & ÀS VEZES & NÃO \\
\hline 1 & $0 \%$ & $2 \%$ & $98 \%$ \\
\hline 2 & $0 \%$ & $6 \%$ & $94 \%$ \\
\hline 3 & $2 \%$ & $10 \%$ & $88 \%$ \\
\hline 4 & $8 \%$ e $6 \%$ * & $38 \%$ & $48 \%$ \\
\hline 5 & $8 \%$ & $20 \%$ & $72 \%$ \\
\hline 6 & $2 \%$ ** & $16 \%$ & $82 \%$ \\
\hline 7 & $6 \%$ e $4 \%$ ** & $6 \%$ & $84 \%$ \\
\hline 8 & $66 \%$ & $0 \%$ & $34 \%$ \\
\hline 9 & $24 \%$ & $12 \%$ & $64 \%$ \\
\hline 10 & $2 \%$ & $2 \%$ & $96 \%$ \\
\hline
\end{tabular}

* dor intensa

**presença de sinal bilateral 
Tabela 5.2 - Freqüência percentual das respostas do questionário anamnésico pelo Grupo II (Classe II sem tratamento ortodôntico)

\begin{tabular}{|c|c|c|c|}
\hline${ }_{\text {Questão }}^{\text {Resposta }}$ & SIM & ÀS VEZES & NÃO \\
\hline 1 & $0 \%$ & $6 \%$ & $94 \%$ \\
\hline 2 & $2 \%$ & $2 \%$ & $96 \%$ \\
\hline 3 & $4 \%$ & $12 \%$ & $84 \%$ \\
\hline 4 & $12 \%$ & $26 \%$ & $63 \%$ \\
\hline 5 & $4 \%$ & $30 \%$ & $66 \%$ \\
\hline 6 & $4 \%$ & $10 \%$ & $86 \%$ \\
\hline 7 & $8 \%$ e $2 \%$ ** & $8 \%$ & $82 \%$ \\
\hline 8 & $60 \%$ & $2 \%$ & $38 \%$ \\
\hline 9 & $32 \%$ & $10 \%$ & $58 \%$ \\
\hline 10 & $2 \%$ & $0 \%$ & $96 \%$ \\
\hline
\end{tabular}

** presença de sinal bilateral 
Tabela 5.3 - Freqüência percentual das respostas do questionário anamnésico pelo Grupo III (Classe I com tratamento ortodôntico)

\begin{tabular}{|c|c|c|c|}
\hline Questão & SIM & ÀS VEZES & NÃO \\
\hline 1 & $0 \%$ & $10 \%$ & $90 \%$ \\
\hline 2 & $0 \%$ & $6 \%$ & $94 \%$ \\
\hline 3 & $2 \%$ & $16 \%$ & $82 \%$ \\
\hline 4 & $8 \%$ e $6 \%$ * & $24 \%$ & $62 \%$ \\
\hline 5 & $6 \%$ & $34 \%$ & $60 \%$ \\
\hline 6 & $6 \%$ & $20 \%$ & $74 \%$ \\
\hline 7 & $10 \%$ e $6 \%$ ** & $16 \%$ & $68 \%$ \\
\hline 8 & $84 \%$ & $8 \%$ & $8 \%$ \\
\hline 9 & $14 \%$ & $16 \%$ & $70 \%$ \\
\hline 10 & $2 \%$ & $2 \%$ & $96 \%$ \\
\hline
\end{tabular}

* dor intensa

**presença de sinal bilateral 
Tabela 5.4 - Freqüência percentual das respostas do questionário anamnésico pelo Grupo IV (Classe II com tratamento ortodôntico)

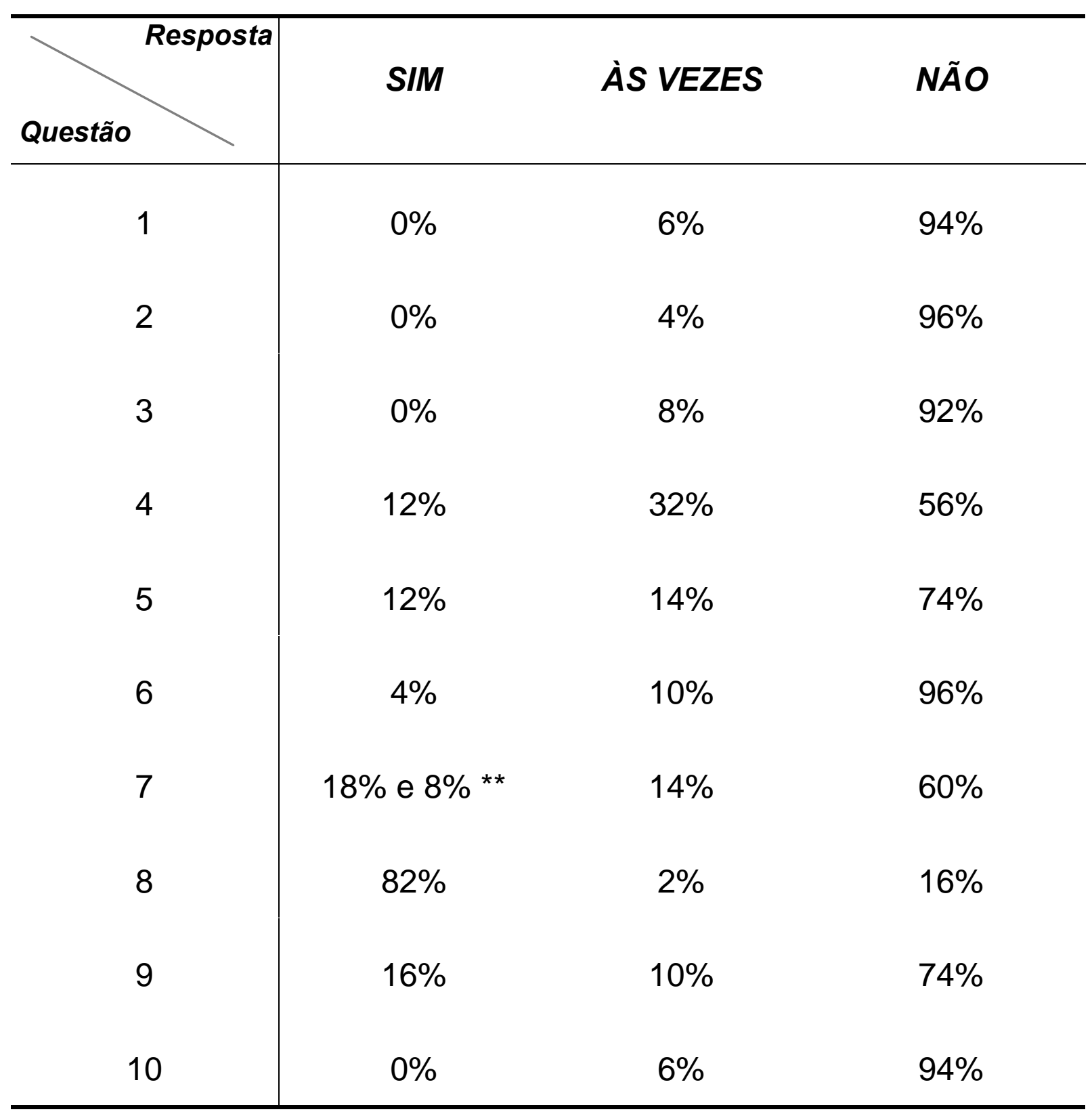

${ }^{* *}$ presença de sinal bilateral 
Somando-se os escores das respostas do questionário anamnésico (2 para a resposta "sim", 1 para a resposta "às vezes" e 0 para a resposta "não"), chegou-se à classificação dos grupos em relação à presença de Disfunção Temporomandibular (tabela 5.5 e figura 5.1).

Tabela 5.5 - Distribuição da amostra, dividida por grupos, em relação ao índice de DTM

\begin{tabular}{c|cccc}
\hline GRUPOS & $\boldsymbol{I}$ & $\boldsymbol{I I}$ & III & IV \\
\hline Ausente & $60 \%(30)$ & $60 \%(30)$ & $62 \%(31)$ & $68 \%(34)$ \\
Leve & $38 \%(19)$ & $34 \%(17)$ & $36 \%(18)$ & $28 \%(14)$ \\
Moderada & $2 \%(1)$ & $6 \%(3)$ & $2 \%(1)$ & $4 \%(2)$ \\
Total & $100 \%(50)$ & $100 \%(50)$ & $100 \%(50)$ & $100 \%(50)$ \\
\hline
\end{tabular}

Os sintomas mais freqüentemente relatados por toda a amostra foram os ruídos articulares e as dores de cabeça com 15,5\% e $10 \%$, respectivamente, observados nas questões 4 e 7 do questionário.

Quando realizado o somatório dos valores das respostas, obteve-se a classificação do índice anamnésico ${ }^{19}$ da seguinte forma, para toda a amostra: DTM ausente, 62,5\%; DTM leve, 34\%; DTM moderada, $3,5 \%$. 


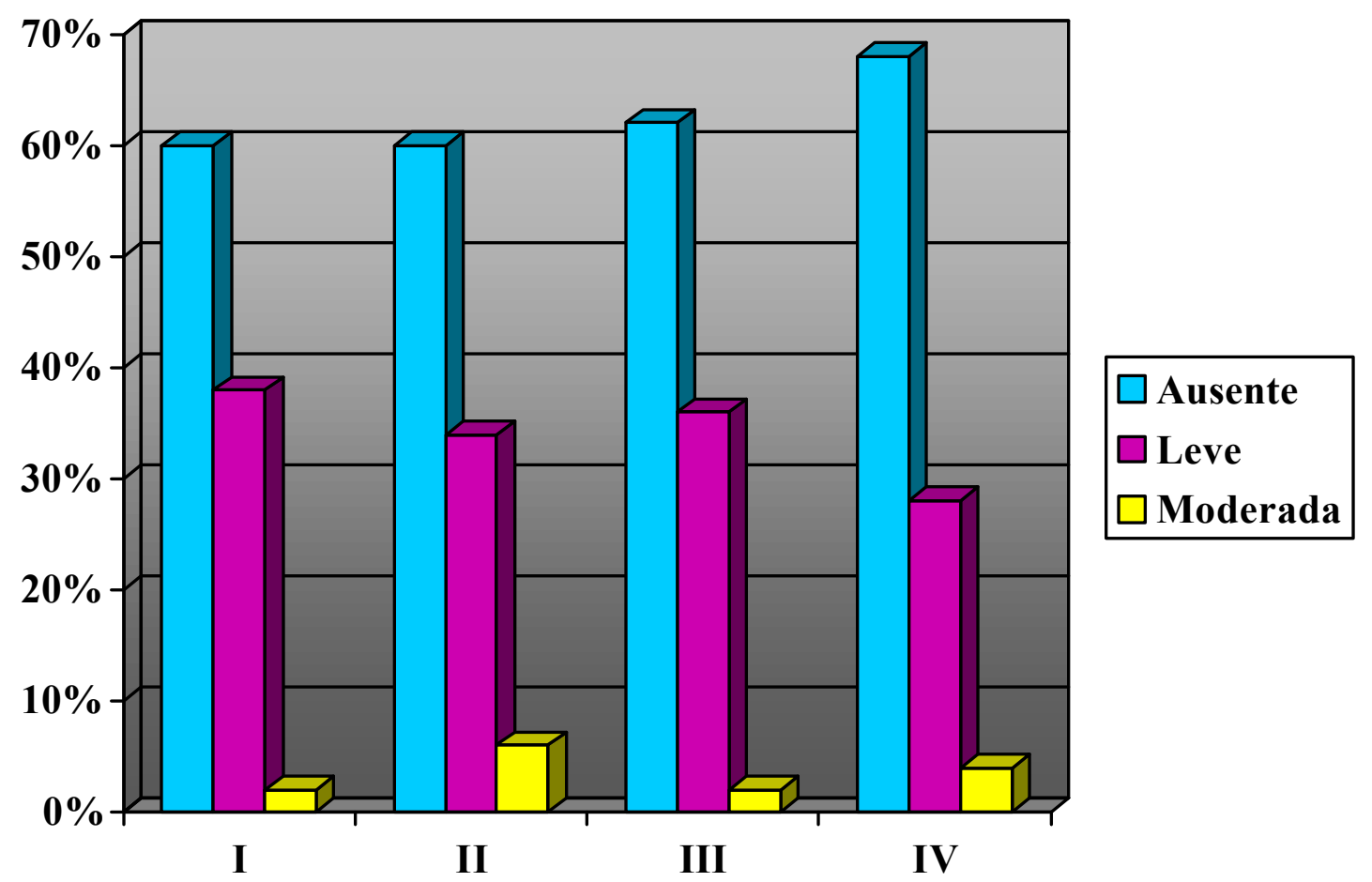

Figura 5.1 - Gráfico da distribuição da amostra, dividida por grupos, em relação ao índice de DTM.

Quando aplicado o teste de Kruskal-Wallis, não se obtiveram diferenças estatisticamente significantes $(p=0,86)$. Observe na figura 5.1 a distribuição homogênea dos indivíduos nos diversos grupos nas classificações de DTM. Nenhum indivíduo foi classificado como portador de "DTM severa", pelo questionário anamnésico.

De toda a amostra, 20,5\% (41) relataram o hábito de ranger os dentes, enquanto 18,5\% (37) relataram o hábito de apertamento dental. No entanto o hábito mais predominante de toda a amostra foi a onicofagia, presente em $46 \%$ (92) da amostra. 

MANDIBULARES

A abertura bucal (ativa) mostrou uma média de 48,2mm $(d p=6,0)$, sendo $47,7 \mathrm{~mm}(\mathrm{dp}=5,3)$ para o grupo I, 48,7mm $(\mathrm{dp}=7,5)$ para o grupo II, 49,6mm (dp=5,9) para o grupo III e 47,6mm $(d p=5,3)$ para o grupo IV.

Os movimentos de lateralidade direita e esquerda apresentaram médias de $9,0 \mathrm{~mm}$ e $8,7 \mathrm{~mm}$ respectivamente, ambas com desvio padrão de $1,7 \mathrm{~mm}$.

No movimento protrusivo a média obtida entre os indivíduos analisados foi de $6,9 \mathrm{~mm}(\mathrm{dp}=2)$. 


\subsection{3 - DADOS RELACIONADOS COM A OCLUSÃO} MORFOLÓGICA

$\mathrm{Na}$ mordida aberta anterior, apenas 5,5\% $(n=11)$ de todos os casos analisados apresentaram esta má oclusão, sendo $10 \%$ $(n=5)$ do grupo I, $4 \%(n=2)$ do grupo II, $2 \%(n=1)$ do grupo III e $6 \%(n=3)$ do grupo IV.

A mordida cruzada posterior mostrou que o grupo I apresentou $30 \%(n=15)$ com mordida cruzada unilateral e $6 \%(n=3)$ com bilateral, o grupo II, $14 \%(n=7)$ e $8 \%(n=4)$ e o grupo IV teve $8 \%(n=4)$ de mordida cruzada unilateral, já o grupo III não apresentou esta má oclusão. O resultado geral foi de $16,5 \%$ ( $n=33$ pacientes) de jovens com mordida cruzada posterior.

O overbite teve uma média geral de $2,8 \mathrm{~mm}(\mathrm{dp}=1,7)$, sendo $3,1 \mathrm{~mm}(\mathrm{dp}=1,8)$ para o grupo I, 3,6mm $(\mathrm{dp}=2,0)$ para o grupo II, $2,4 \mathrm{~mm}(\mathrm{dp}=1,1)$ para o grupo III e 2,4mm $(\mathrm{dp}=1,3)$ para o IV. Quando submetidos ao teste de Kruskal-Wallis, os grupos demonstraram diferença estatística significante, com exceção da comparação entre os grupos III e IV $(p<0,02)$.

No overjet o valor médio encontrado foi $3,3 \mathrm{~mm}$ $(\mathrm{dp}=2,0)$ : o grupo I apresentou 3,1 $\mathrm{mm}(\mathrm{dp}=1,6)$, o grupo II, 5,6mm $(d p=2,3)$; o grupo III 2,4mm $(d p=0,9)$ e o grupo IV 2,4mm $(d p=1,0)$. Por apresentarem resultados diferentes entre si, foram também submetidos ao teste de Kruskal-Wallis, apresentando resultados estatisticamente significantes, com exceção dos grupos III e IV $(p<0,02)$. 


\subsection{4 - DADOS RELACIONADOS COM OS ASPECTOS}

OCLUSAIS

O número de contatos na posição de máxima intercuspidação habitual mostrou uma média geral de 6,2 contatos $(d p=2,3)$ para a amostra geral e 5,5 $(d p=1,8)$ para o grupo I, 6,1 $(d p=2,7)$ para o grupo II, 6,4 $(\mathrm{dp}=2,1)$ para o grupo III e $7,1(\mathrm{dp}=2,4)$ para o grupo IV.

O teste de Kruskal-Wallis também demonstrou uma diferença estatística significante entre todos os grupos $(p<0,01)$, com exceção do II e III.

$\mathrm{Na}$ discrepância entre as posições de relação cêntrica (RC) e máxima intercuspidação habitual (MIH), 91\% ( $n=182)$ dos indivíduos analisados apresentaram discrepância de 0-2mm, sendo representados por $94 \%(n=47)$ do grupo I, 90\% $(n=45)$ do grupo II, 96\% $(n=48)$ do grupo III e $84 \%(n=42)$ do grupo IV. A diferença entre RC e $\mathrm{MIH}$ de 2-4mm, observaram-se por ordem crescente dos grupos, respectivamente, os valores $6 \%(n=3), 8 \%(n=4), 4 \%(n=2)$ e $16 \%(n=8)$, resultando em $8,5 \%(n=17)$ da amostra geral. Dos 200 pacientes apenas $0,5 \%(n=1)$, pertencente ao grupo II, demonstrou mais de $4 \mathrm{~mm}$ de discrepância de RC para MIH. De toda a amostra estudada 46,5\% $(\mathrm{n}=93)$ apresentavam $\mathrm{RC}$ e $\mathrm{MIH}$ coincidente, sendo 44\% $(\mathrm{n}=22)$ para o grupo I, 48\% (n=24) para o II, 46\% ( $n=23)$ para o III e 48\% $(n=24)$ para o IV. 
Quanto ao guia lateral direito, os resultados indicaram $41,5 \%(n=83)$ da amostra apresentava desoclusão pelo canino, 32\% $(n=64)$, desoclusão em grupo e $26,5 \% \quad(n=53)$ não tinham guia. Considerando os grupos I, II, III, IV observou-se: 28\% (14), 22\% (11), $58 \%$ (29) e 58\% (29) com desoclusão pelo canino; 34\% (17), 46\% (23), $24 \%$ (12) e 24\% (12) com desoclusão em grupo; e 38\% (19), 32\% (16), $18 \%$ (9) e $18 \%$ (9) não realizavam esses tipos de desoclusão lateral direita.

Os resultados da avaliação do guia lateral esquerdo, nos grupos I, II, III e IV foram respectivamente: 34\% (17), 26\% (13), 58\% (29) e $62 \%$ (31) com desoclusão pelo canino; 14\% (7), 42\% (21), 18\% (9) e $26 \%$ (13) com desoclusão em grupo; e 52\% (26), 32\% (16), 24\% (12) e $12 \%$ (6) sem estas guias laterais. Analisando a amostra como um todo obtiveram-se: $45 \%$ (90) com guia canino, 25\% (50) com função em grupo e $30 \%(60)$ sem esses tipos de guias.

Ao analisar os tipos de guia lateral independente do lado obteve-se os seguintes resultados para a amostra como um todo: $43,25 \%$ com guia canino, 38,5\% com função em grupo e $28,25 \%$ não apresentavam esses guias. Nos grupos I, II, III, IV os resultados por grupos foram respectivamente: $31 \%, 24 \%, 58 \%$ e $60 \%$ com guia canino; $24 \%, 44 \%, 21 \%$ e $25 \%$ com desoclusão em grupo e $45 \%, 32 \%, 21 \%$ e $15 \%$ sem esses tipos de guia.

Considerando a amostra como um todo, obtiveram-se $79 \%$ (158) com guia anterior, sendo $72 \%$ (36) do grupo I, $74 \%$ (37) do 
grupo II (73\% dos jovens não tratados), 86\% (43) do III e 84\% (42) do IV (85\% dos pacientes tratados). Entre os indivíduos sem guia, 28\% (14) eram do grupo I, 26\% (13) do II (27\% dos jovens não tratados), 14\% (7) do III e $16 \%$ (8) do IV (15\% dos pacientes tratados), enquanto $21 \%$ (42) representavam a amostra geral.

A análise dos contatos em lado de não-trabalho direito, mostrou que 62\% ( $n=124)$ dos indivíduos não apresentavam contatos, 22\% (44) tinham interferência, porém mantinham a desoclusão no lado de trabalho e 16\% (32) demonstraram interferência, impedindo a desoclusão. Os valores obtidos por grupo foram:

$\begin{array}{ccccc} & \text { I } & \text { II } & \text { III } & \text { IV } \\ \text { Ausente } & 48 \%(24) & 54 \%(37) & 64 \%(32) & 62 \%(31) \\ \text { Presente com guia } & 18 \%(9) & 16 \%(8) & 26 \%(13) & 28 \%(14) \\ \text { Presente sem guia } & 34 \%(17) & 10 \%(5) & 10 \%(5) & 10 \%(5)\end{array}$

Quanto aos contatos em lado de não trabalho esquerdo, os valores da amostra total foram $63,5 \%$ (127) sem interferência, 22,5\% (45) com guia e 13,5\% (27) sem guia. Os grupos se comportaram da seguinte maneira:

$\begin{array}{ccccc} & \text { I } & \text { II } & \text { III } & \text { IV } \\ \text { Ausente } & 54 \%(27) & 72 \%(36) & 62 \%(31) & 66 \%(33) \\ \text { Presente com guia } & 22 \%(11) & 14 \%(7) & 28 \%(14) & 26 \%(13) \\ \text { Presente sem guia } & 24 \%(12) & 14 \%(7) & 10 \%(5) & 8 \%(4)\end{array}$

Avaliando estes resultados independente dos lados direito ou esquerdo obteve-se: $63 \%$ da amostra não apresentou contatos 
no lado de não trabalho, $22 \%$ tinham contatos que não impediam a desoclusão e 15\% apresentavam interferências que impediam a desoclusão. Os resultados apresentados, pelos grupos I, II, III e IV respectivamente foram: $41 \%, 63 \%, 63 \%$ e $64 \%$ sem contatos, $20 \%$, $15 \%, 25 \%$ e $27 \%$ com contatos que não impediam o guia de desoclusão e $29 \%, 12 \%, 10 \%$ e $9 \%$ com interferências impedindo a desoclusão. 
5.1.5 - DADOS RELACIONADOS COM O AJUSTE OCLUSAL E AS FACETAS DE DESGASTE

Os pacientes submetidos ao ajuste oclusal (grupos III e IV), apresentaram uma prevalência de $6 \%$ (6), sendo 5 do grupo III (10\%) e 1 do grupo IV (2\%).

No que diz respeito ao número de facetas de desgaste oclusal, observou-se que 164 (82\%) dos indivíduos apresentavam de 0 a 4 facetas, sendo 45 (90\%) do grupo I, 45 (90\%) do grupo II, 38 (76\%) do grupo III e 36 (72\%) do grupo IV. Na amostra geral 24 (12\%) tinham de 4 a 10 facetas, sendo, 2 (4\%) do grupo I, 5 (10\%) do grupo II, $6(12 \%)$ do grupo III e $11(22 \%)$ do grupo IV; e apenas $12(6 \%)$ tinham mais que 10 facetas de desgaste, distribuídos em $3(6 \%)$ do grupo I, 6 (12\%) do grupo III e $3(6 \%)$ do grupo IV. No entanto um total de $112(56 \%)$ não apresentavam nenhuma faceta, sendo $35(70 \%)$ do grupo I, 34 (68\%) do grupo II, 22 (44\%) do grupo III e 21 (42\%) do grupo IV. 


\section{2 - RESULTADOS ANALÍTICOS}

As diferentes variáveis foram comparadas, individualmente, aos índices de DTM (ausente, leve e moderada), com o objetivo de elucidar a relação existente entre eles.

Quando correlacionados o índice de DTM aos valores de overjet e overbite, não se observou associação entre os mesmos, como observado nas figuras 5.2 e 5.3 .

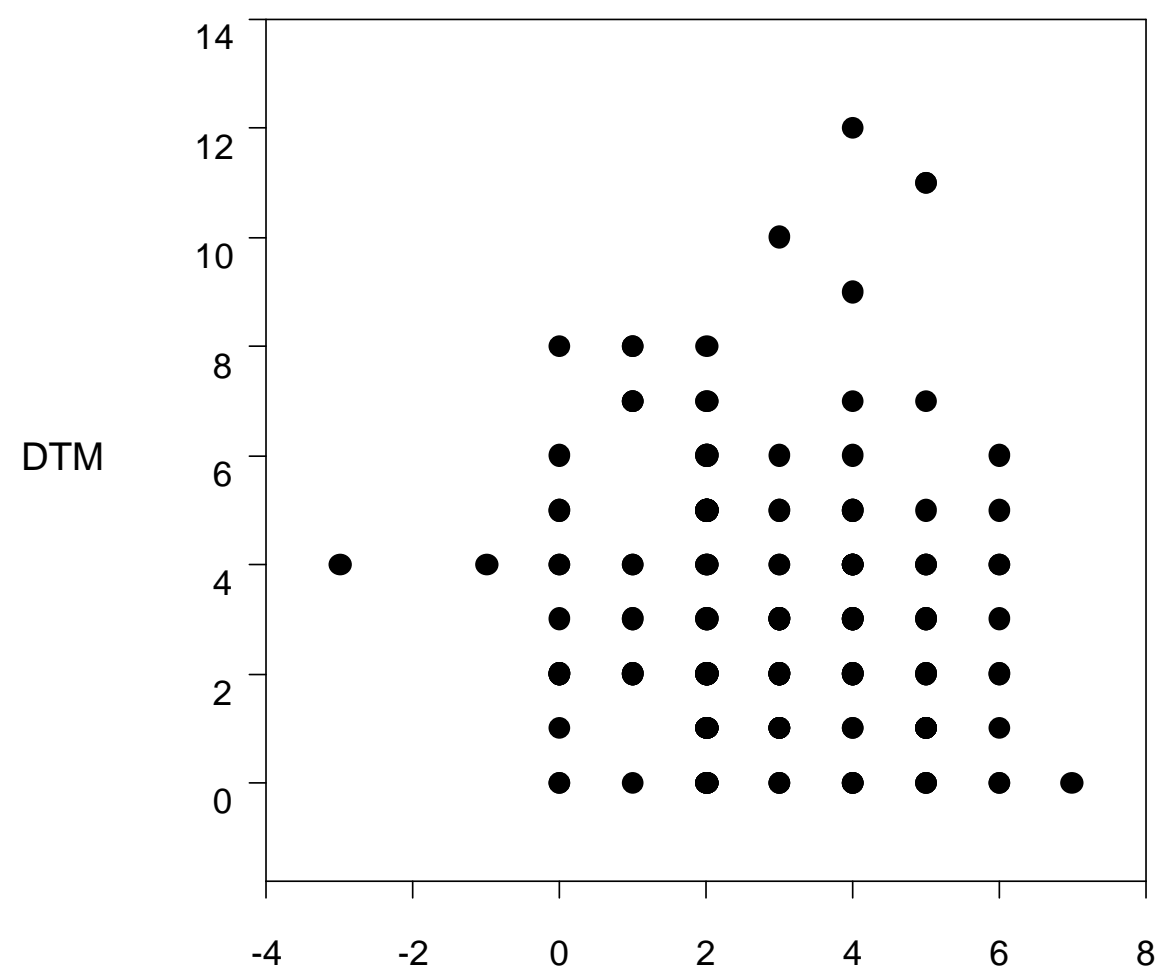

Overbite

Figura 5.2 - Correlação entre o overbite e o grau de DTM 


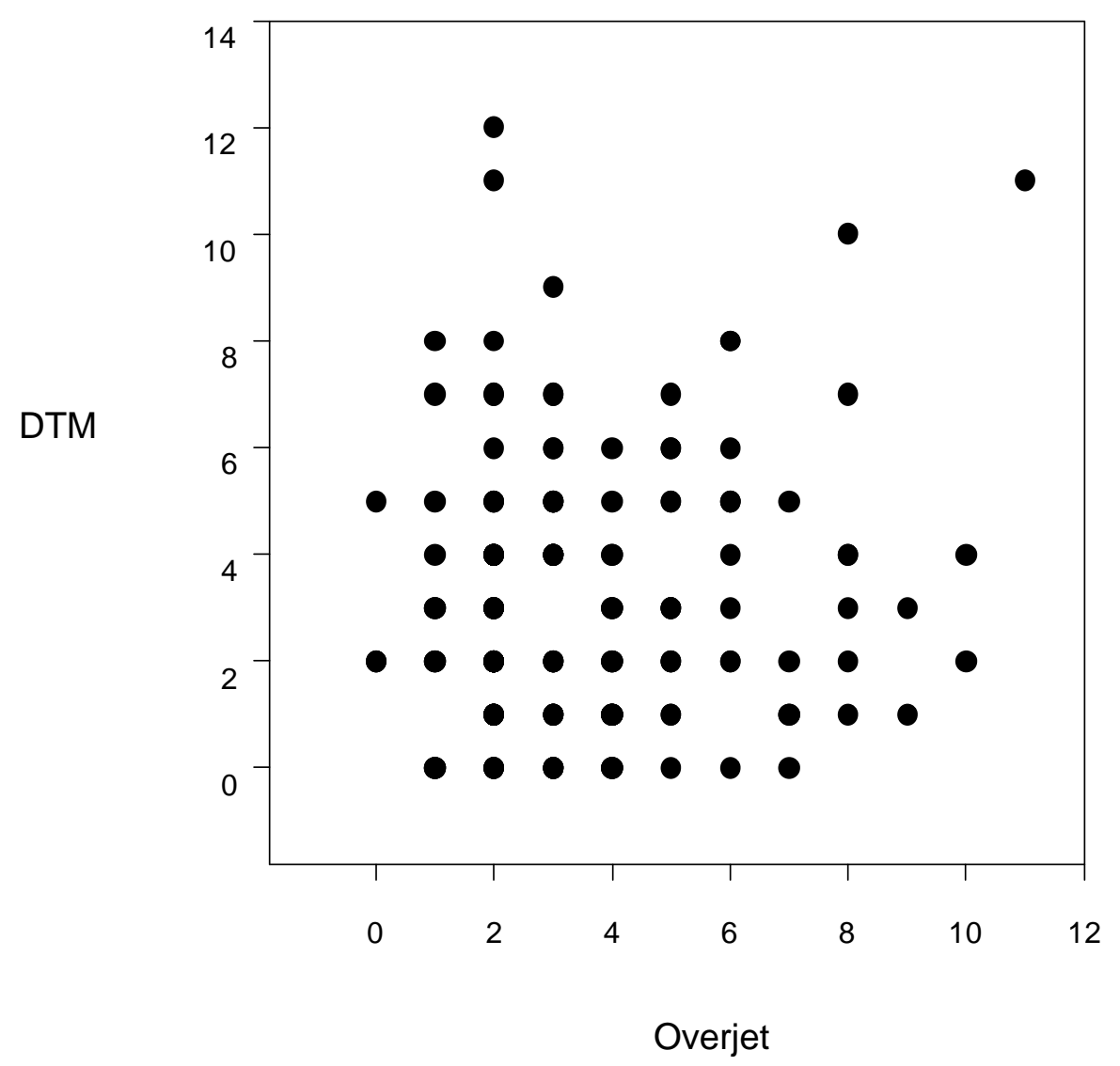

Figura 5.3 - Correlação entre o overjet e o grau de DTM

Os valores obtidos da associação entre a mordida aberta anterior e o índice de DTM encontram-se na tabela 5.6.

Quando aplicado o teste de qui-quadrado, não se constatou uma associação significante $(p=0,09)$. 
Tabela 5.6 - Relação entre a mordida aberta anterior (MAA) e o grau de DTM

\begin{tabular}{c|cccc}
\hline MAA & Ausente & Leve & Moderada & Total \\
\hline Presente & $36,4 \%(4)$ & $63,6 \%(7)$ & $0 \%$ & $100 \%(11)$ \\
Ausente & $64 \%(121)$ & $32,3 \%(61)$ & $3,7 \%(7)$ & $100 \%(189)$ \\
\hline
\end{tabular}

A tabela 5.7 mostra a freqüência de pacientes com e sem mordida cruzada posterior nas diferentes intensidades de DTM.

O teste qui-quadrado não detectou também uma associação estatisticamente significante $(p=0,81)$.

Tabela 5.7 - Relação entre a mordida cruzada posterior(MCP) e o grau de DTM

\begin{tabular}{c|cccc}
\hline DTM & Ausente & Leve & Moderada & Total \\
\hline Ausente & $61,7 \%(103)$ & $34,1 \%(57)$ & $42 \%(7)$ & $100 \%(167)$ \\
Unilateral & $65,4 \%(17)$ & $34,6 \%(9)$ & $0 \%$ & $100 \%(26)$ \\
Bilateral & $71 \%(5)$ & $28,6 \%(2)$ & $0 \%$ & $100 \%(7)$ \\
\hline
\end{tabular}

( ) número de indivíduos 
A discrepância entre as posições de relação cêntrica (RC) e máxima intercuspidação habitual (MIH) estão descritas na tabela 5.8 e figura 5.2 .

O teste de qui-quadrado não revelou uma associação estatisticamente significante $(p=0,9)$.

Tabela 5.8 - Relação entre a discrepância de RC para MIH e o grau de DTM

\begin{tabular}{c|cccc}
\hline DTM & Ausente & Leve & Moderada & Total \\
\hline DISCREPÂNCIA & & & & \\
\hline 0 a $2 \mathrm{~mm}$ & $62,1 \%(113)$ & $34,6 \%(63)$ & $3,3 \%(6)$ & $100 \%(182)$ \\
2 a $4 \mathrm{~mm}$ & $64,7 \%(11)$ & $29,4 \%(5)$ & $5,9 \%(1)$ & $100 \%(17)$ \\
& & & & \\
Mais de $4 \mathrm{~mm}$ & $100 \%(1)$ & $0 \%$ & $0 \%$ & $100 \%(1)$ \\
\hline
\end{tabular}

( ) freqüência em número de indivíduos 


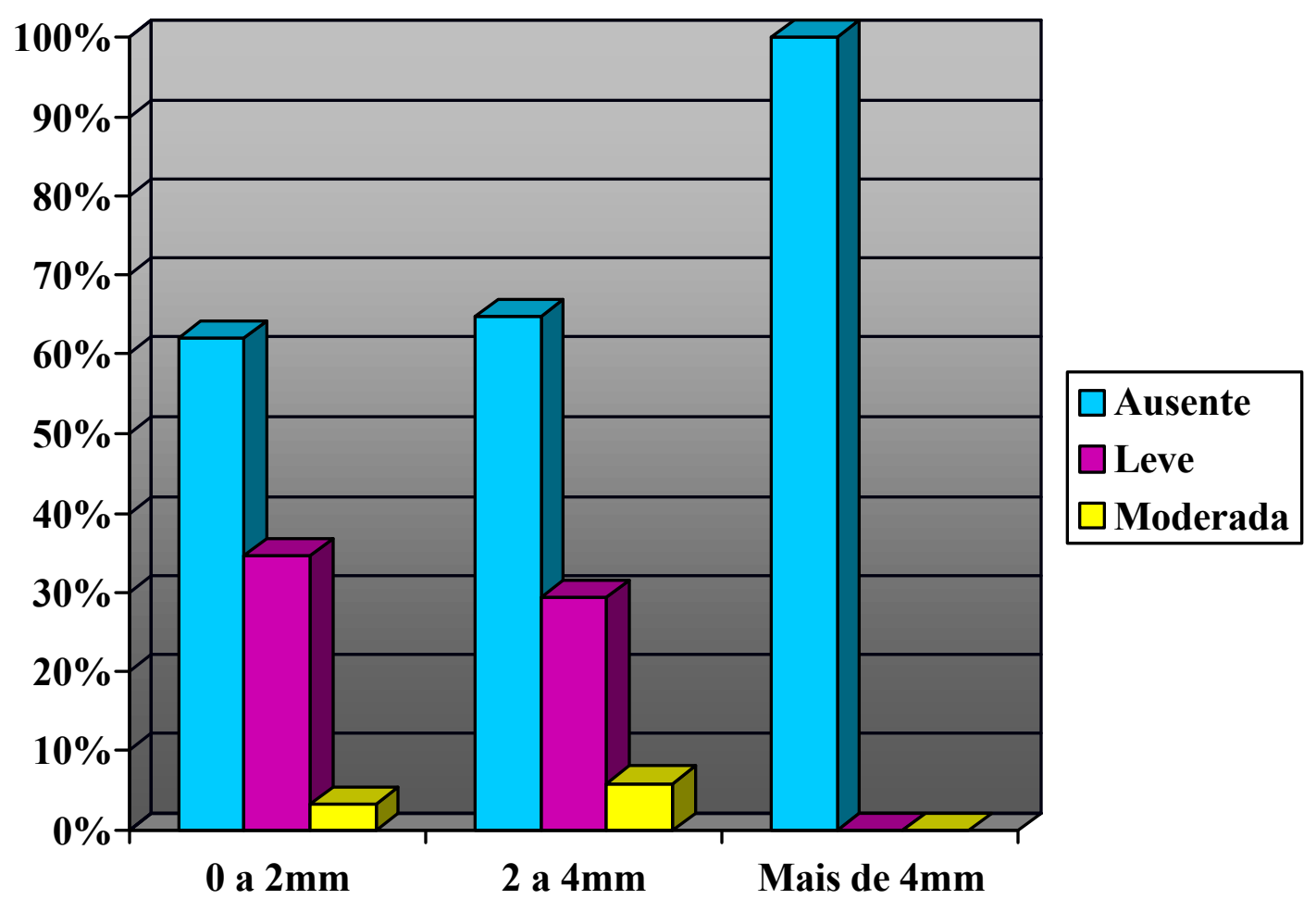

Figura 5.4 - Gráfico da relação entre a discrepância de RC para MIH e o índice de DTM.

Os movimentos de guia lateral direita e esquerda foram analisadas em conjunto para a comparação do índice de DTM (tabela 5.9).

O teste de qui-quadrado não constatou associação estatisticamente significante $(p=0,61)$. 
Tabela 5.9 - Relação entre o guia lateral e o grau de DTM

\begin{tabular}{|c|c|c|c|c|}
\hline$\overbrace{\text { GUIA LATERAL }}^{D T M}$ & Ausente & Leve & Moderada & Total \\
\hline Ausente & $70 \%(28)$ & $30 \%(12)$ & $0 \%$ & $100 \%(40)$ \\
\hline Unilateral & $60,6 \%(20)$ & $36,4 \%(12)$ & $3 \%(1)$ & $100 \%(33)$ \\
\hline Bilateral & $60,7 \%(77)$ & $34,6 \%(44)$ & $4,7 \%(6)$ & $100 \%(127)$ \\
\hline
\end{tabular}

$\mathrm{Na}$ tabela 5.10 e figura 5.3 encontram-se descritas a freqüência e a porcentagem de pacientes com guia anterior, em relação ao grau de DTM.

Quando aplicado o teste de qui-quadrado observou-se associação estatisticamente significante $(p=0,05)$. 
Resultados

Tabela 5.10 - Relação entre o guia anterior e o grau de DTM*

\begin{tabular}{c|cccc}
\hline GUIA ANTERIOR & Ausente & Leve & Moderada & Total \\
\hline Ausente & $47,6 \%(20)$ & $50 \%(21)$ & $2,4 \%(1)$ & $100 \%(42)$ \\
& & & & \\
Presente & $66,5 \%(105)$ & $29,7 \%(47)$ & $3,8 \%(6)$ & $100 \%(158)$ \\
\hline
\end{tabular}

( ) número de indivíduos * Estatisticamente significante

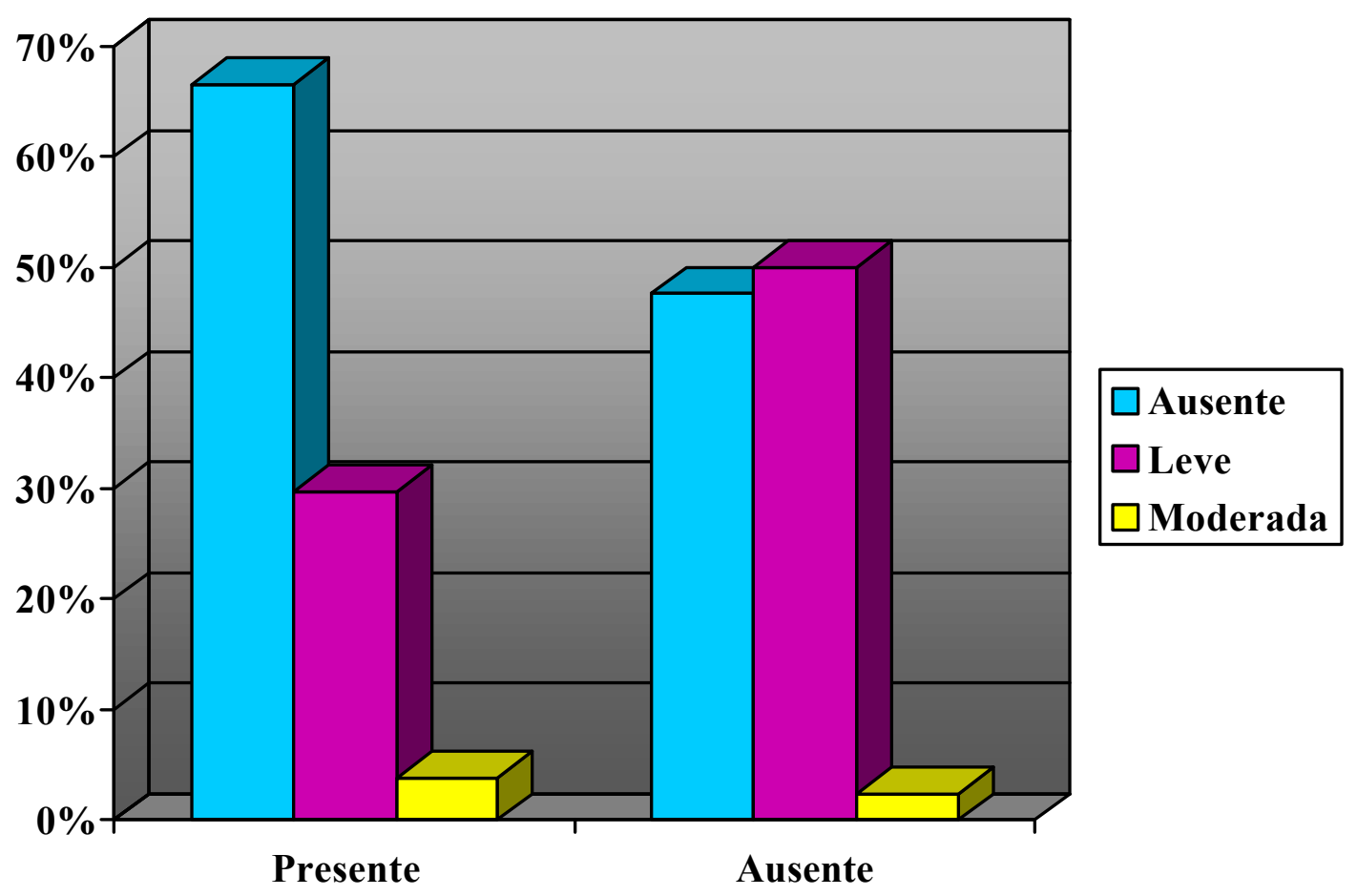

Figura 5.5 - Gráfico da relação entre guia anterior e DTM 
Os contatos em não-trabalho (direito e esquerdo) foram comparados ao índice de Disfunção Temporomandibular (tabela 5.11) e quando submetidos ao teste de qui-quadrado, não se observaram diferenças estatisticamente significantes $(p=0,47)$.

Tabela 5.11 - Relação entre os contatos oclusais em não-trabalho e o grau de DTM

\begin{tabular}{c|cccc}
\hline CONTATOS & Ausente & Leve & Moderada & Total \\
\hline Ausente & $67 \%(71)$ & $29,2 \%(31)$ & $3,8 \%(4)$ & $100 \%(106)$ \\
Unilateral & $64 \%(25)$ & $33,3 \%(13)$ & $2,6 \%(1)$ & $100 \%(39)$ \\
& & & & \\
Bilateral & $52,7 \%(29)$ & $43,7 \%(24)$ & $3,6 \%(2)$ & $100 \%(55)$ \\
\hline ( ) número de indivíduos & & & \\
\hline
\end{tabular}

A relação entre 0 ajuste oclusal, pós-tratamento ortodôntico e o índice de Disfunção Temporomandibular encontram-se descritos na tabela 5.12.

O teste qui-quadrado não constatou associação estatisticamente significante $(p=0,16)$. 
Tabela 5.12 - Relação entre o ajuste oclusal e o grau de DTM

\begin{tabular}{c|cccc}
\hline AJUSTE & Ausente & Leve & Moderada & Total \\
\hline Ausente & $62,4 \%(121)$ & $34,5 \%(67)$ & $3,1 \%(6)$ & $100 \%(194)$ \\
Presente & $66,6 \%(4)$ & $16,7 \%(1)$ & $16,7 \%(1)$ & $100 \%(6)$ \\
\hline & & & & \\
\hline
\end{tabular}

Os valores relacionados às facetas de desgaste e 0 índice de DTM apresentam-se descritos na tabela 5.13. Submetidos ao teste de qui-quadrado não se constatou associação estatisticamente significante $(p=0,51)$.

Tabela 5.13 - Relação entre facetas de desgaste e o grau de DTM

\begin{tabular}{c|cccc}
\hline & Ausente & Leve & Moderada & Total \\
\hline FACETAS & & & & \\
\hline 0 a 4 & $64,1 \%(105)$ & $32,8 \%(54)$ & $3,1 \%(5)$ & $100 \%(164)$ \\
& $50 \%(12)$ & $41,6 \%(10)$ & $8,4 \%(2)$ & $100 \%(24)$ \\
Mais que 10 & $66,6 \%(8)$ & $33,4 \%(4)$ & $0 \%$ & $100 \%(12)$ \\
\hline ( ) número de indivíduos & & & \\
\hline
\end{tabular}


Discussão 


\section{6 - DISCUSSÃO}

A relação entre as Disfunções Temporomandibulares e o tratamento ortodôntico tem despertado um grande interesse nos últimos anos, quando inúmeras pesquisas procuram esclarecer a controvérsia sobre esta possível relação.

O estudo dos efeitos do tratamento ortodôntico sobre as DTM começou a merecer uma maior atenção por parte da classe ortodôntica a partir do momento que os processos judiciais foram movidos, atribuindo ao tratamento ortodôntico, o surgimento de sinais e sintomas de DTM.

Neste trabalho foi realizada uma avaliação comparativa entre a oclusão e a realização do tratamento ortodôntico com a prevalência dos sinais e sintomas de DTM. A amostra, dividida em grupos tratados e não tratados, viabilizou a análise do tratamento ortodôntico como prevenção, cura ou causa das DTM.

\section{1 - DADOS GERAIS E PREVALÊNCIA DE DTM}

O questionário anamnésico aplicado neste trabalho foi respondido de forma auto-aplicável por todos os pacientes e os dados, expressos em porcentagem, se encontram nas tabelas 5.1, 5.2, 5.3 e 5.4 (p.60, 61, 62, 63). O somatório das respostas destes questionários forneceram a classificação do índice de DTM em ausente, leve, moderada e severa. FONSÊCA; BONFANTE; VALLE ${ }^{36}$ mostraram, em 
1994, que a classificação de DTM obtida pelo índice anamnésico, uma forma simplificada quando comparada com o exame clínico, apresentava grau de confiabilidade de 95\%. Este questionário pode ser incorporado ao exame ortodôntico inicial, complementando a documentação ortodôntica, pois suas informações são extremamente importantes para o ortodontista.

Os resultados nos mostram que nos 4 grupos estudados encontraram-se $62,5 \%$ do total da amostra sem DTM; com DTM leve foi encontrada em $34 \%$ e moderada em apenas 3,5\%, ao passo que a DTM severa não foi encontrada em nenhum paciente, independente do grupo. Em termos de necessidade de tratamento, aceita-se que apenas os pacientes portadores de DTM severa ou moderada precisam de intervenção direta, enquanto que os portadores de DTM leve precisam predominantemente de orientação e autoconhecimento (SHIFFMAN et $\left.\mathrm{al}^{109}\right)$.

Quando esses dados foram submetidos à análise estatística, não se encontraram resultados significantes, observando-se uma distribuição homogênea dos indivíduos dos diversos grupos no que se refere à classificação, indicando que a movimentação ortodôntica, isoladamente, não é capaz de provocar DTM. Essa classificação é bastante clara na figura 5.1 (p.65). Este dado também nos mostra que o tratamento ortodôntico não foi responsável pela cura ou prevenção da

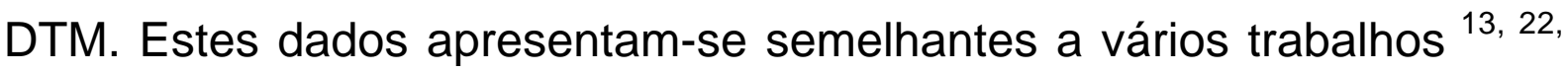
$60,64,72,76,97,108,121,122$ 
Levando-se em conta a totalidade da amostra observase que 75 indivíduos apresentaram algum grau de DTM, o que corresponde a 37,5\% da amostra. Esses valores mostram quão comuns são os sinais e sintomas de DTM e, com certeza pode-se afirmar, quão negligenciados são pelos profissionais, pois além de tudo se trata de uma amostra com faixa etária aquém da idade predominante para apresentar DTM. É porém nessa idade que surgem os primeiros sinais e sintomas, que se agravarão posteriormente se não forem cuidados adequadamente. Assim, a detecção precoce da DTM, de maneira simplificada como a permitida pelo índice anamnésico, possibilitaria uma abordagem preventiva levando à limitação dos danos, como sugerido por FONSÊCA; BONFANTE; VALLE ${ }^{36}$, FONSÊCA et $\mathrm{al}^{38}$. Cabe ao ortodontista diagnosticar os sinais e sintomas de DTM, para esclarecer e orientar o paciente, independente da fase de tratamento em que 0 paciente se encontra. Devido à duração do tratamento ortodôntico, dois anos em média, a omissão do profissional, quanto a esses dados, pode proporcionar dissabores ao ortodontista, inclusive gerando ações legais causadoras de danos morais e econômicos.

A porcentagem de indivíduos com DTM moderada e severa de $10 \%$ no estudo de WIGDOROWICZ-MAKOWEROWA ${ }^{125}$, e de $13 \%$ com DTM moderada no trabalho de WÄNMAN; AGERBERG ${ }^{124}$, diferem dos 3,5\% com DTM moderada encontrada neste estudo. Esta diferença pode estar relacionada à amostra, sendo que metade dos indivíduos eram menores de 15 anos, portanto abaixo da idade de maior risco de desenvolver DTM. 
A idade média geral da amostra estudada (14,7 anos), variando de 12,4 (grupos I e II) a 17,3 e 17,4 (grupos III e IV, respectivamente) está aquém ou no início da faixa etária que $R U G H$; SOLBERG ${ }^{105}$ consideraram ser o alvo das DTM, ou seja, mulheres entre as idades de 15 a 40 anos, muito embora autores como HELÖE; HELÖE $^{52}$ e RIEDER; MARTINOFF; WILCOX ${ }^{102}$ tenham afirmado que o fator idade parece não afetar a freqüência dos sinais e sintomas.

\section{2 - MOVIMENTOS MANDIBULARES}

Os dados relacionados com as ATMs mostraram que a abertura bucal ativa média da amostra foi de 48,3mm, variando de 47,6mm (grupo IV) a 49,6mm (grupo III). A tomada destas medidas, realizada de acordo com a proposição de RIEDER ${ }^{101}$, não encontrou diferenças entre os grupos. Isso significa que o grau de DTM eventualmente presente, não foi capaz de provocar limitação significativa da abertura bucal, independente do tipo de má oclusão (Classe I ou II) e do tratamento ortodôntico (realizado ou não).

A abertura bucal ativa tem sido descrita em vários estudos, variando de $43,3 \mathrm{~mm}$ a $60 \mathrm{~mm}$ e seriam indicativos de alguma alteração nos componentes do sistema estomatognático se fosse inferior a $40 \mathrm{~mm}$ (SOLBERG ${ }^{116}$ ). Visto que o valor médio nos indivíduos sem DTM é de 50mm ou mais, como comentado por FONSÊCA; PAIVA; BONFANTE $^{37}$, em 1991, os valores são muito próximos dos encontrados neste trabalho. 
Em 1983, GRIFFITHS ${ }^{43}$ mostrou que a média normal do movimento lateral situa-se entre 7 e $16 \mathrm{~mm}$, sendo que valores inferiores a $7 \mathrm{~mm}$ podem ser indicativos de alteração muscular e/ou articular, assim como impedimento mecânico (processo coronóide, estilóide). Neste trabalho, encontrou-se média de $9 \mathrm{~mm}$ para o movimento lateral direito e $8,7 \mathrm{~mm}$ para o esquerdo, o que os situa dentro dos padrões de normalidade em todos os grupos. O mesmo ocorreu com o movimento protrusivo, cuja média entre os pacientes foi de $6,9 \mathrm{~mm}$.

\section{3 - OCLUSÃO MORFOLÓGICA}

Com relação à mordida aberta anterior, apenas 11 casos (5,5\%) de toda a amostra estudada apresentavam este tipo de má oclusão, sendo 7 dos grupos I e II (não tratados) e 4 dos grupos III e IV (tratados ortodonticamente). Surpreendentemente, percebe-se que este tipo de má oclusão não foi corrigida pelo tratamento ortodôntico ou sofreu recidiva, pois se esperava ausência dessa relação inconveniente, ou seja, ausência de guia anterior, nos grupos III e IV. Por ser conseqüência dos hábitos de interposição lingual durante a deglutição ou fonação, de respiração bucal, e até mesmo de sucção digital, segundo ALMEIDA; URSI ${ }^{5}$, representa uma má oclusão de difícil controle que apresenta recidiva, se não controlada a causa e pode representar um fator de risco para a DTM (EGERMARK et $\mathrm{al}^{33}$ ), contudo quando avaliada isoladamente não pode ser considerada como causa da Disfunção Temporomandibular (PULLINGER; SELIGMAN ${ }^{92}$ ). Assim sendo, seria interessante e útil discutir previamente com os pacientes portadores desse tipo de relacionamento oclusal, a dificuldade de 
corrigí-lo e mantê-lo, evitando retratamentos ortodônticos sucessivos, sujeitando os dentes e ligamento periodontal às seqüelas eventualmente provocadas por esses atos. Ainda, o conhecimento e a discussão prévia das dificuldades do tratamento, podem evitar conflitos desagradáveis na relação paciente-profissional.

Eventualmente pacientes portadores de mordida aberta poderiam ser beneficiados pela sua redução com o uso do ajuste oclusal, como comentado por BONFANTE et al ${ }^{15}$, em 1998.

A análise da tabela 5.6 (p.75) mostra que nenhum paciente apresentava mordida aberta anterior e DTM moderada. Dos 11 pacientes portadores da mordida aberta 7 tinham DTM leve e 4 ausente, o que caracteriza ausência de fator de risco para esta amostra e faixa etária; este resultado está de acordo com os achados de PULLINGER; SELIGMAN ${ }^{92}$, 1991, ao concluírem que a mordida aberta não pode ser considerada, isoladamente como causa da DTM. Por outro lado, RIOLO; BRANDT; TENHAVE ${ }^{104}$, em 1987, demonstraram associação entre a mordida aberta e a dor muscular e articular. Acredita-se que a mordida aberta não possa ser considerada como causa dos sinais e sintomas de DTM, mas quando não tratada dificulta a mastigação, e se associada a outros fatores pode aumentar o risco de DTM. Segundo MCNAMARA JÚNIOR; SELIGMAN; OKESON a mordida aberta anterior esquelética está associada a artropatias da ATM e pode ser o resultado de alterações ósseas e ligamentosas da ATM. 
A mordida cruzada posterior unilateral foi encontrada em $22 \%$ dos jovens dos grupos I e II (22 indivíduos) e em 7\% (7 indivíduos) dessa amostra ela era bilateral. Essa má oclusão estava ausente nos pacientes do grupo III e $8 \%$ da amostra do grupo IV a apresentava unilateralmente. Independente de terem ou não recebido tratamento ortodôntico e de serem portadores de Classe I ou II, 16,5\% da amostra apresentava esta má oclusão. Percebe-se claramente aqui os efeitos benéficos da ortodontia na correção desse problema, haja vista a diferença na incidência deste relacionamento anômalo entre os arcos nos grupos tratados ou não.

Apesar da alta incidência da mordida cruzada posterior, não houve associação estatisticamente significante com o grau de DTM (tabela 5.7, p.75), como citado por SELIGMAN; PULLINGER ${ }^{111}$, em 1991. Cento e sessenta e sete indivíduos da amostra apresentavam relação posterior dos arcos normal e dos 26 nos quais essa relação era cruzada unilateral, 17 apresentavam ausência de DTM e apenas 9 tinham grau leve; tanto quanto uni ou bilateral, nenhum a apresentava de forma moderada, o que também demonstra a incompatibilidade de se correlacionar a mordida cruzada posterior, uni ou bilateral, com o grau de DTM.

O overbite da amostra variou de 2,4mm (grupos III e IV) a 3,6mm (grupo II), ficando o grupo I com valor intermediário de 3,1 mm. A análise estatística mostrou diferenças entre os grupos tratados (III e IV) e não tratados ortodonticamente (grupos I e II), com média de $3,35 \mathrm{~mm}$ de overbite. De maneira similar ao ocorrido com a mordida 
cruzada posterior, percebe-se aqui que os efeitos do tratamento ortodôntico são capazes de gerar modificações significativas no overbite.

Quando correlacionado o índice de DTM aos valores de overbite (figura 5.2, p.73), não se observou associação entre eles, provavelmente por serem valores próximos ao normal como comentado por PULLINGER; SELIGMAN², em 1991, inferior ao valor encontrado por LIEBERMAN et $\mathrm{al}^{66}$, responsável pela correlação positiva entre 0 overbite maior ou igual a $5 \mathrm{~mm}$ e DTM.

Os mesmos resultados e relação de significância estatística foram detectados com relação ao overjet, pois os grupos tratados ortodonticamente apresentavam 2,4mm de trespasse, enquanto os grupos I e II, sem tratamento, apresentavam variação de $3,3 \mathrm{~mm}$ (grupo I) a 5,6mm (II). Também aqui se visualizam os efeitos da ortodontia na correção desse relacionamento dos arcos, capaz de provocar redução de mais de $100 \%$ nos valores do overjet, como ocorrido nos pacientes do grupo II.

Em 1992, FONSÊCA ${ }^{35}$ encontrou valores de $2,66 \mathrm{~mm}$ para o overbite e $2,95 \mathrm{~mm}$ para o overjet em pacientes sintomáticos com idade média de 30,2 anos, não se diferenciando dos valores encontrados em amostras assintomáticas, como descrito por FONSÊCA; PAIVA; BONFANTE ${ }^{37}$ e SELIGMAN; PULLINGER ${ }^{111}$. 
A figura 5.3 (p.74) demonstra a não associação entre os valores do overjet e o índice de DTM. Entre os 200 pacientes encontrouse uma média de $3,3 \mathrm{~mm}$ de overjet, muito próximo do normal (PULLINGER; SELIGMAN ${ }^{92}$ ). Em 1997, HENRIKSON; EKBERG; NILNER ${ }^{53}$ relataram que valores superiores a $6 \mathrm{~mm}$ aumentam o risco de DTM e em $1998^{54}$ observaram que pacientes com overjet, também neste valor, apresentam mastigação deficiente.

A análise dos valores permite a observação de que, se a ortodontia é capaz de posicionar corretamente os dentes, tanto no sentido vertical quanto no horizontal, tem dificuldades de mantê-los em posição, quando se analisa conjuntamente esses dados com a mordida aberta anterior, nos quais mais da metade da amostra que a apresentava, sofreram recidiva (4 em 7 pacientes). Tal fato nos revela a importância em esclarecer, ao paciente, as limitações do tratamento ortodôntico quanto a sua estabilidade.

\section{$6.4-$ ASPECTOS OCLUSAIS}

Em 1990, KORIOTH ${ }^{63}$ comentou ser média de 14 o número de contatos dentários em $\mathrm{MIH}$, variáveis de acordo com a força exercida. Neste trabalho, encontrou-se média geral de 6,2 contatos dentários efetivos, sendo que os grupos não tratados (l e II) apresentaram 5,8 contatos (abaixo da média) e os III e IV média de 6,7 contatos dentários, havendo diferença entre os grupos do ponto de vista estatístico, exceto entre o II e o III, semelhante aos valores encontrados por HENRIKSON; EKBERG; NILNER ${ }^{54}$, durante a obtenção dos 
contatos por pressão leve. Os dados obtidos por RIISE; ERICSSON ${ }^{103}$, em 1983, também mostraram que a pressão leve gerou 8 pontos de contato, enquanto a intensa permitiu 16. Talvez este achado sirva de alerta para que a ortodontia se preocupe em melhorar esse relacionamento entre os dentes, pois a estabilidade oclusal depende da bilateralidade e simultaneidade dos contatos, menos do que do próprio número, mas é um fator relevante a se levar em conta o conceito de oclusão ideal teorizado por OKESON ${ }^{88}$, em 1992.

Durante anos, a discrepância entre as posições de RC e MIH sustentou a teoria oclusal de etiologia de DTM, como comentado por MCNEILL ${ }^{78}$, em 1990. Dos 200 casos analisados, 93 apresentavam coincidência entre as posições de $\mathrm{RC}$ e $\mathrm{MIH}$, posição conhecida por ORC (OKESON $\left.{ }^{88}, 1992\right)$, sendo 22 para o grupo I, 24 para o grupo II, 23 para o grupo III e 24 para o IV. Observa-se assim que o tratamento ortodôntico, se não foi capaz de aumentar o número de pacientes portadores de ORC (oclusão de relação cêntrica), como observado por JANSON; MARTINS ${ }^{57}$, onde $85 \%$ dos pacientes examinados não apresentavam esta posição ao término do tratamento, também não provocou discrepâncias entre $\mathrm{RC}$ e $\mathrm{MIH}$ maiores do que as encontradas nos grupos não tratados ( $\mathrm{l}$ e II), conforme relatado por HWANG; BEHRENTS $^{55}$. Esses valores são significativamente maiores do que os normalmente relatados na literatura, pois $B{ }^{2}$ RON $^{12}$ (1969) e RIEDER $^{100}$ (1978) encontraram entre 10 a $14 \%$ de pacientes com coincidência das posições, entretanto PULLINGER et al $^{96}$ (1987) encontraram dois terços da amostra com $\mathrm{RC}$ e $\mathrm{MIH}$ coincidente ou com discrepância de até $0,5 \mathrm{~mm}$. 
Entre os pacientes que apresentavam grau de discrepância variável de 0,1 a mais de $4 \mathrm{~mm}$ (apenas 1 ), a maior parte apresentava discrepância de até $2 \mathrm{~mm}(91 \%)$ e apenas $8,5 \%$ da amostra geral tinha diferença entre $\mathrm{RC}$ e $\mathrm{MIH}$ variável de 2 a $4 \mathrm{~mm}$. Talvez essa discrepância de valores, quando comparada com os dados encontrados na literatura, se deva à dificuldade de se obter um relaxamento suficiente dos pacientes, durante a avaliação da RC, capaz de tornar detectáveis ou perceptíveis pequenos desajustes. Muito provavelmente as pequenas diferenças, talvez predominantes na amostra, tenham sido consideradas coincidências. Vale ressaltar que os pacientes não foram submetidos a qualquer tratamento prévio à determinação da $\mathrm{RC}$, como a confecção e uso de dispositivos como preconizado por LUCIA ${ }^{71}, 1960$ (JIG) ou LONG ${ }^{70}, 1973$ (tiras de acetato) e isto pode ter contribuído para que as posições de $\mathrm{MIH}$ fossem consideradas ORC.

A discrepância de RC para MIH não apresentou relação estatisticamente significante com o grau de DTM, pois dos 182 pacientes que apresentavam ORC ou distância de até $2 \mathrm{~mm}$ entre as posições, apenas 6 apresentavam DTM moderada, 63 leve e 113 ausente. Quando a distância entre as posições de RC para $\mathrm{MIH}$ era maior (2 a 4mm) podendo ser considerada fator de risco por MCNAMARA JÚNIOR; SELIGMAN; OKESON ${ }^{76}$ (1995), apenas 17 pacientes a apresentavam sendo 1 com DTM moderada, 5 com leve e 11 ausente (tabela 5.8, p.76).

O desgaste oclusal seletivo, indicado como terapia pós tratamento ortodôntico, tem como finalidade refinar o padrão oclusal, 
levando o paciente a uma ORC. Aos pacientes com discrepância de até $2 \mathrm{~mm}$ esta terapia é viável, contudo não está indicada, pois considera-se esta discrepância normal, incapaz de provocar danos ao paciente. Para o caso com discrepância de 2 a $4 \mathrm{~mm}$ ou mais, o desgaste oclusal está indicado, entretanto nem sempre este se torna viável, visto que para alcançar a ORC pode ser necessário desgastes excessivos em esmalte, chegando muito próximo a dentina. Neste caso o tratamento mais adequado, em discrepâncias muito graves seria o retratamento ortodôntico.

O guia canino, foi detectado em $41,5 \%$ da amostra, quando considerado o lado direito e 45\% quando considerado o esquerdo. O guia por função em grupo foi encontrado em $32 \%$ da amostra para o lado direito e $25 \%$ para o esquerdo, enquanto outros tipos de guia, ou mesmo sua ausência foram encontrados em $26,5 \%$ dos pacientes para o lado direito e $30 \%$ para o esquerdo.

Quando se leva em conta os grupos não tratados ortodonticamente encontra-se $31 \%$ dos pacientes com guia canino bilateralmente no grupo I e $24 \%$ no II. Quando se considerou os grupos tratados ortodonticamente, $58 \%$ dos pacientes do grupo III apresentaram guia canino e $60 \%$ do grupo IV. Esses dados comprovam de maneira inequívoca a eficiência do tratamento ortodôntico no restabelecimento deste guia, extremamente importante para 0 preenchimento dos princípios da oclusão ideal (OKESON ${ }^{88}$ ) ou mutuamente protegida (MCNEILL ${ }^{79}$ ). BELSER; HANNAM ${ }^{11}$ (1985) relataram que a função em grupo aumenta a atividade dos músculos 
Discussão

elevadores da mandíbula, enquanto o guia canino minimiza esta atividade. Observa-se aqui, a importância em se proporcionar a desoclusão lateral pelo guia canino ao final do tratamento ortodôntico, facilmente conseguida com o correto posicionamento do braquete no canino. A colagem, incorreta, mais para a incisal no canino, causa uma intrusão neste dente, proporcionando uma desoclusão em grupo.

Analisando-se a função em grupo, 24\% da amostra do grupo I apresenta este tipo de desoclusão, enquanto o grupo II apresentou 44\% dos pacientes com esta desoclusão. Chama a atenção, nesse grupo de pacientes não tratados, a quantidade de casos (quase o dobro) com função em grupo (grupo II), devido a má oclusão Classe II de Angle que inviabiliza os guias anterior e lateral pelos caninos. Os grupos tratados ortodonticamente apresentam $21 \%$ de indivíduos portadores da função em grupo, no III e $25 \%$ no IV, tratamento esse que possibilitou o aumento do número de pacientes com guia canino.

Outros tipos de guia ou sua ausência, motivada por contatos de não trabalho, estavam presentes em $45 \%$ da amostra do grupo I e $32 \%$ do II, representando os pacientes não tratados ortodonticamente; após tratamento o grupo III apresentava ausência ou outro tipo de guia em $21 \%$ da amostra, enquanto o IV apresentava $15 \%$, dados cuja análise possibilita a afirmativa de que apenas metade dos pacientes sem outros tipos de guia ou ausência não se beneficiaram do tratamento ortodôntico com relação a esse aspecto. 
Os dados relativos aos guias canino e em grupo, ou mesmo outros tipos de guia ou a ausência deles, foram analisados com relação à DTM e estão representados na tabela 5.9 (p.78), não demonstrando relação estatística entre estes valores. Dos 200 pacientes, 127 apresentam guia bilateral (canino ou grupo), sendo que em seis indivíduos se detectou DTM moderada, em 44 leve e ausente nos demais; quando o guia não estava presente ou era diferente dos aqui estudados, de um total de 40 indivíduos nenhum tinha DTM moderada, 12 leve e 28 não a apresentavam.

Apesar dos benefícios do tratamento ortodôntico com relação à obtenção de guias, vale a pena ressaltar que, com esses dados, pelo menos 20 pacientes dos 100 que constituíam os grupos III e IV, tratados ortodonticamente, deixaram de ter suas oclusões protegidas pelo guia canino. Se isso não significa relação com DTM, significa possibilidades de forças oblíquas que seriam melhor dissipadas e com menor intensidade, se a desoclusão ocorresse nos caninos, como discutido por D'AMICO ${ }^{23}$ desde 1958 .

O guia anterior estava presente em $79 \%$ da amostra, com média de $73 \%$ nos grupos não tratados ortodonticamente e $85 \%$ nos grupos após tratamento. Observa-se que os benefícios do guia anterior, um dos requisitos da oclusão ideal, foi obtido apenas por pouco mais de $10 \%$ da amostra tratada. A ausência do guia anterior foi notada em $27 \%$ da amostra que não recebeu tratamento e $15 \%$ da amostra tratada ortodonticamente. 
Numa análise geral, pode se observar que o tratamento ortodôntico foi eficiente no restabelecimento do guia anterior em 85\% dos casos e apenas em 59\% deles foi também capaz de restabelecer a guia canino, o que permite a consideração de que a estética tenha sido privilegiada em detrimento da fisiologia ou função do sistema estomatognático.

Esta afirmativa se consolida na tabela 5.10 e figura 5.5 (p.79), que mostram a associação estatisticamente significante entre o guia anterior e o grau de DTM. De acordo com MCNAMARA JÚNIOR; PULLINGER; OKESON ${ }^{76}$ a ausência de guia anterior é um dos fatores de risco das DTM. Observa-se que, dos 42 pacientes sem guia, 22 apresentavam algum grau de DTM, representando mais da metade (52,4\%) da amostra; dos 158 pacientes que tinham guia anterior, 53 apresentavam algum grau de DTM e representavam 33,5\% da amostra.

Interferências do lado de não-trabalho, ainda encontrado na literatura como lado de balanceio, são tidas como potencialmente traumáticas e capazes de provocar danos aos componentes do sistema estomatognático (LINDHE; NYMAN ${ }^{67}$, MCNEILL $^{79}$ ).

Indivíduos sem interferência foram encontrados em $63 \%$ da amostra, enquanto $22 \%$ apresentavam contatos do lado de nãotrabalho, mantendo a desoclusão do lado oposto e 15\% apresentavam interferência que impedia desoclusão. 
No tempo decorrido do tratamento ortodôntico e nas faixas etárias do trabalho, a presença de interferências no lado de nãotrabalho não apresentou relação estatisticamente significante com as DTM, conforme se visualiza na tabela 5.11 (p.80), de acordo com BUSH $^{16}$ e MAGNUSSON; ENBON ${ }^{73}$. Dos 55 pacientes com interferências bilaterais, 2 apresentavam DTM moderada, enquanto 4 dos 106 indivíduos sem interferências também apresentavam DTM com o mesmo grau; considerando os indivíduos com DTM leve, 24 tinham interferências bilaterais e 31 não as apresentavam. Esta não associação entre as interferências e as DTM talvez se explique devido à capacidade adaptativa do sistema mastigatório à situação oclusal, como comentada por INGERVALL; CARLSSON ${ }^{56}$. Entretanto as interferências oclusais podem causar danos locais como facetas de desgaste, sobrecarga localizada em apenas um dente e ainda alterações periodontais que causam mobilidade dentária. Tais alterações podem passar desapercebidas durante anos e se tornam graves a longo prazo. As interferências oclusais podem ser corrigidas, durante 0 tratamento ortodôntico, com a alteração do torque que pode posicionar o dente de tal forma que estas interferências sejam evitadas.

\section{5 - AJUSTE OCLUSAL E FACETAS DE DESGASTE}

ARNOLD ${ }^{8}$, em 1927, foi o primeiro autor a preconizar ajuste oclusal pós ortodontia, a fim de distribuir as forças mastigatórias entre o maior número de dentes possível. Embora o ajuste oclusal ainda seja controverso, pode ser recomendado para muitos casos ortodônticos 
com o intuito de corrigir relações oclusais e distribuir forças nos dentes posteriores, como recomendado por JANSON et $\mathrm{al}^{58}$.

Dos 100 pacientes tratados ortodonticamente (grupos III e IV), apenas 6 (5 do grupo III) tiveram indicação e receberam ajuste oclusal; devido à pequena amostra não se encontrou correlação estatística significante entre o ajuste oclusal e a DTM, conforme observa-se na tabela 5.12 (p.81). FORSSEL; KIRVESKARI; KANGASNIEMI $^{39}$, JANSON; MARTINS ${ }^{57}$, KIRVESKARI; ALANEM; JAMSA $^{62}$ observaram que o ajuste oclusal foi eficiente na redução dos sinais e sintomas de DTM, porém FORSSEL; KIRVESKARI; KANGASNIEMI $^{39}$ ressaltaram ainda a efetividade do tratamento placebo.

O ajuste oclusal é um tratamento definitivo e irreversível, necessitando uma análise cuidadosa para a sua indicação. Alguns dos objetivos do ajuste oclusal são melhorar a estabilidade estrutural, otimizando a distribuição de forças e melhorar a harmonia funcional durante a mastigação, deglutição e fonação. Sua indicação envolve evidências de traumatismos oclusais que prejudicam a saúde periodontal do paciente ${ }^{79}$. Sugere-se que o ortodontista realize 0 desgaste seletivo quando, ao final do tratamento, houver uma interferência grosseira, capaz de desestabilizar o funcionamento do sistema estomatognático. Uma reavaliação do caso está indicada após o término do tratamento ortodôntico, pois durante o período de contenção ocorre uma acomodação dos dentes melhorando o relacionamento oclusal, o que dispensa o ajuste oclusal imediato, quando da remoção do aparelho ortodôntico. 
A importância dos hábitos parafuncionais na etiologia das DTM é amplamente reconhecida na literatura, contudo não devem ser consideradas isoladamente, conforme comprovam os trabalhos de DAO; LUND; LAVIGNE ${ }^{24}$ e PULLINGER; SELIGMAN ${ }^{93}$.

Numa análise geral da tabela 5.13 (p.81) observa-se que 164 pacientes apresentavam até 4 facetas de desgaste e, desse total, a maioria (105) não tinham DTM, sendo que 54 a apresentavam em grau leve, e 5 moderado; 24 possuíam 4 a 10 facetas parafuncionais e em apenas 2 observava-se DTM moderada, 10 leve e o restante, ausência de sinais e sintomas; os pacientes com mais de 10 facetas, em número de 12 , destes 4 eram portadores de DTM leve.

Numa análise dos grupos, observa-se que o I e o II, não tratados ortodonticamente possuíam, respectivamente, 35 e 34 indivíduos sem qualquer faceta; nos grupos III e IV encontraram-se 22 e 21 pacientes, respectivamente, sem estas facetas. Observa-se com isto que nos 5 anos que separam as amostras dos grupos I e II (idade média 12,4 anos) e III e IV (17,4 anos) houve um aumento médio de 13 indivíduos com facetas provocadas por hábitos parafuncionais, ou seja, cerca de $20 \%$ dos pacientes que não as apresentavam, desenvolveramnas.

O hábito mais predominante de toda a amostra foi a onicofagia, presente em $46 \%$ da amostra, enquanto o de apertar dentes foi observado em 18,5\%. Dos hábitos mais danosos por gerar esforços predominantemente oblíquos sobre os dentes, o de ranger estava 
presente em 41 indivíduos. Este resultado deve ser ressaltado para chamar a atenção dos ortodontistas ao fato de observar-se o aumento do estresse e ansiedade, causados pela fase pré-vestibular, necessidade de definições da vida profissional, dentre outros fatores, que ocasionam em geral aumento da carga emocional e com o envolver da idade os pacientes podem exacerbar hábitos potencialmente nocivos, para os quais poderia estar indicada a utilização de placas oclusais, para a prevenção de desgaste anormais, principalmente o dos guias laterais (caninos), como observaram SELIGMAN; PULLINGER; SOLBERG ${ }^{114}$ e anterior (incisivos).

Apesar dessas observações relacionando a presença de facetas com a DTM, não houve associação estatisticamente significante entre estes fatores.

\section{6 - CONSIDERAÇÕES GERAIS}

EGERMARK; INGERVALL; CARLSSON ${ }^{32}$ ressaltaram uma maior importância da má oclusão funcional na existência das DTM, no entanto os diferentes tipos de má oclusão morfológica (Classes II e III, mordida aberta anterior e mordida cruzada posterior), quando associados à má oclusão funcional, podem criar uma predisposição às Disfunções Temporomandibulares, o que demonstra a etiologia multifatorial destas disfunções.

A etiologia multifatorial das $\mathrm{DTM}^{2}, 31,81,83$ não permite que se considere um fator isoladamente como causal da disfunção, 
onde se deve enfatizar a relevância dos fatores pscicoemocionais no desenvolvimento da $\mathrm{DTM}^{4}, 41,44,125$, o que impossibilita considerar a oclusão, de modo isolado, na participação da severidade da DTM, conforme descrito por CONTI et al ${ }^{19}$, em 1996. Os sinais e sintomas das DTM podem ser explicados pela influência de uma combinação de fatores como idade, interferências oclusais, atividade motora e fatores psicológicos $^{4,32}$. PULLINGER; SELIGMAN ${ }^{94}$ em 2000, consideraram que algumas alterações oclusais podem ser conseqüência da DTM, contrariando os achados de RICKETTS ${ }^{99}$ que considerou a oclusão o fator principal dos distúrbios da ATM.

Embora as DTM possam ocorrer em qualquer faixa etária, a estudada permanece abaixo da qual ela se manifesta com mais intensidade, que é dos 25 aos 40 anos (RUGH; SOLBERG $\left.{ }^{105}\right)$. É possível perceber, que muitos dos sinais e sintomas que os pacientes apresentarão futuramente, com o desenvolvimento de graus mais acentuados de DTM, tem ou terão seu início na idade da amostra analisada, principalmente a do gênero feminino. Esses sinais presentes nessa idade, podem se tornar sintomas de DTM ou mesmo permanecerem como sinais e provocarem perdas significativas de estrutura dentária devido a presença dos hábitos. Assim, o diagnóstico precoce destes sinais, numa faixa etária que poderia ser considerada de risco, possibilitaria a adoção de medidas preventivas, ao invés das reparadoras que se toma normalmente na população adulta.

Entre as medidas preventivas ou reparadoras das DTM, não está indicado o tratamento ortodôntico, como citado por 
SADOWSKY; POLSON ${ }^{108}$, pois encontra-se a mesma prevalência desta disfunções em pacientes tratados ortodonticamente ou não.

O ortodontista procura sempre finalizar o tratamento obedecendo as seis chaves da oclusão normal, propostas por ANDREWS $^{6}$, contudo ele se esquece de proporcionar uma boa oclusão funcional ao paciente, como recomendada por OKESON ${ }^{88}$, que será um dos fatores, mais importantes, responsável pelo bom funcionamento do sistema mastigatório. 
Conclusão 


\section{6 - CONCLUSÃO}

Tendo em vista os resultados obtidos no presente trabalho, pôde-se concluir que:

6.1 - Não houve diferença significante na prevalência de DTM entre os grupos estudados.

6.2 - Com relação aos aspectos oclusais e a DTM, não se encontrou relação estatisticamente significante entre pacientes tratados ortodonticamente ou não, nos seguintes aspectos:

a) Número de contatos na posição de $\mathrm{MIH}$;

b) Discrepância entre as posições de $\mathrm{RC}$ e $\mathrm{MIH}$;

c) Contatos no lado de não trabalho;

d) Tipo de guia lateral;

Encontrou-se relação estatisticamente significante entre a ausência de guia anterior e a presença de sinais e sintomas de DTM;

6.3 - Não houve relação entre a DTM e a oclusão morfológica (mordida aberta anterior, mordida cruzada posterior, overjet e overbite) e

6.4 - O ajuste oclusal e a presença de facetas de desgaste não apresentaram-se relacionados ao grau de DTM. 
Anexos 
Data: 1

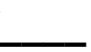

Grupo:

$\mathbf{N}^{0}$ do arquivo:

\section{UNIVERSIDADE DE SÃO PAULO \\ FACULDADE DE ODONTOLOGIA DE BAURU}

Nome: Data nascimento:

Endereço: Bairro:

Cidade: Estado: CEP: Fone res.:

Nome do responsável:

Endereço de trabalho: Fone:

Telefone para recados: Idade: sexo: Má oclusão inicial

\section{ANAMNESE}

1. Você sente dificuldade de abrir a boca?

2. Você sente dificuldade de movimentar sua mandíbula para os lados?

3. Você sente desconforto ou dor muscular quando mastiga?

4. Você sente dores de cabeça com freqüência ?

5. Você sente dores no pescoço e/ou ombros ?

6. Você sente dores de ouvido ou próximo a ele ?

7. Você percebe algum ruído na ATM ?

8. Você considera sua mordida "normal" ?

9. Você usa apenas um lado de sua boca para mastigar?

10. Você sente dores na face ao acordar?

11. Você se considera uma pessoa tensa?

12. O tratamento ortodôntico melhorou, piorou ou não Modificou os seus sintomas?

13. Você apresenta algum dos seguintes hábitos?
Ranger dentes
Mascar chicletes
Apertar dentes
Uso contínuo de telefone
Roer unhas
Uso contínuo do computador
Morder objetos
outros 
Revisão dos sistemas:

NEG POS

NEG

POS

Cardiovascular

Digestivo

Musculoesqueletal

Qual?

\section{EXAME CLÍNICO}

\section{AVALIAÇÃO DA ATM:}

a) Movimentação

DOR

ABERTURA MÁXIMA

(incluindo trespasse)

LATERALIDADE DIREITA

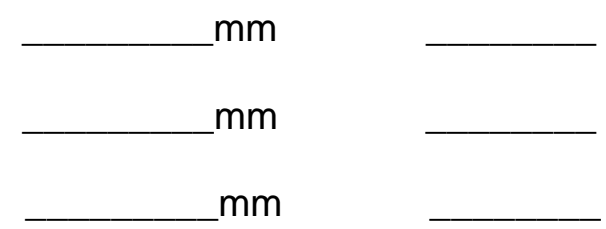

PROTRUSÃO

Endócrino

Respiratório

Neurológico

LATERALIDADE ESQUERDA

ABERTURA: Simétrica

$\begin{array}{lll}\text { Desvio } & \text { Direita } & \text { Esquerda } \\ \text { Deflexão } & \text { Direita } & \text { Esquerda }\end{array}$

b) Ruídos articulares

ABERTURA

ESTALIDO Direito Esquerdo Direito Esquerdo

CREPITAÇÃO Direito Esquerdo

HIPERMOBILIDADE Direito Esquerdo

c) Palpação da ATM:

\begin{tabular}{|c|c|c|}
\hline & Direita & Esquerda \\
\hline Aspecto lateral & & \\
\hline Aspecto posterior & & \\
\hline
\end{tabular}




\section{EXAME MUSCULAR:}

Temporal

Anterior

Médio

Posterior
DIREITO

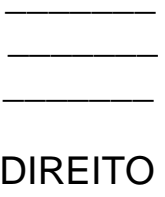

ESQUERDO

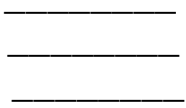

ESQUERDO

\section{Masseter superficial}

Origem

Médio

Posterior

Masseter profundo

Digástrico posterior

Esternocleidomastoideo Trapézio (superior)
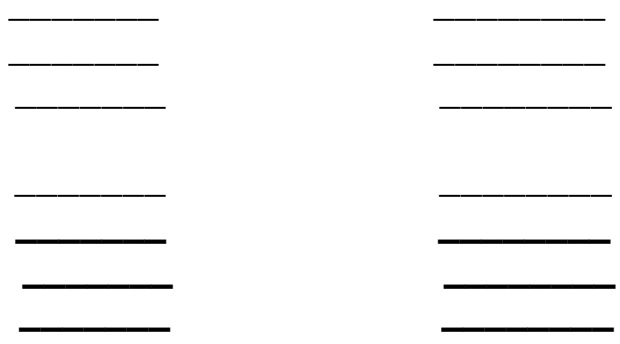

3. AVALIAÇÃO DENTAL E OCLUSAL:

$\mathbf{X}=$ Ausente/extraído $\quad \mathbf{F}=$ Faceta de desgaste

$\mathbf{E}=$ Em erupção

\begin{tabular}{l|l|l|l|l|l|l|l|l|l|l|l|l|l|l|l}
18 & 17 & 16 & 15 & 14 & 13 & 12 & 11 & 21 & 22 & 23 & 24 & 25 & 26 & 27 & 28 \\
\hline 48 & 47 & 46 & 45 & 44 & 43 & 42 & 41 & 31 & 32 & 33 & 34 & 35 & 36 & 37 & 38
\end{tabular}

\begin{tabular}{l|l|l|l|l|l|l|l|l|l}
55 & 54 & 53 & 52 & 51 & 61 & 62 & 63 & 64 & 65 \\
\hline 85 & 84 & 83 & 82 & 81 & 71 & 72 & 73 & 74 & 75
\end{tabular}

NÚMERO DE DENTES AUSENTES: $\quad 0-4$

$4-10$

$+10$

TRESPASSE VERTICAL: $\mathrm{mm}$

TRESPASSE HORIZONTAL: $\mathrm{mm}$

Mordida aberta anterior

Mordida cruzada unilateral

Mordida cruzada bilateral
RELAÇÃO SAGITAL Classe I

Até $1 / 2$ Classe II

mais de $1 / 2$ Classe II 
TIPO DE APARELHO:

Fixo com $A E B$ _ hs. sem $A E B$

Fixo + outro aparelho ortopédico com AEB_h_ hs. sem AEB removível

RELAÇÕES MAXILOMANDIBULARES:

$$
\mathrm{RC}=\mathrm{MIH}
$$

Discrepância vertical:

$\begin{array}{lll}0-2 \mathrm{~mm} & 2-4 \mathrm{~mm} & >4 \mathrm{~mm}\end{array}$

GUIA LATERAL DIREITA

Ausente

Guia canino

Função em grupo

GUIA ANTERIOR

Presente

Ausente

INTERFERÊNCIAS EM NÃO-TRABALHO DIREITO

Não

Sim

Com guia

Sem guia

INTERFERÊNCIAS EM NÃO-TRABALHO ESQUERDO

Não

Sim

Com guia

Sem guia

NÚMERO DE CONTATOS EM MIH:

AJUSTE OCLUSAL Sim

Não 
Sim meses

TÉRMINO DO TRATAMENTO HÁ meses, usando contenção Não

EXTRAÇÃO DE PRÉ-MOLARES

Sim

Superior

Não

Inferior 


\section{Referências Bibliográficas}




\section{REFERÊNCIAS BIBLIOGRÁFICAS ${ }^{*}$}

1. AGERBERG,G.; CARLSSON,G.E. Functional disorders of te masticatory system. I - Distribuition of symptoms according to age and Sex as judged from investigation by questionaire. Acta odont. Scand., v.30, n.6, p.597-613, 1972.

2. AGERBERG,G.; CARLSSON,G.E. Functional disorders of te masticatory system. II - Symptoms inrelation impaired mobility of the mandible as judged from investigation by questionaire. Acta odont. Scand., v.31, n.6, p.335-47, 1973.

3. AGERBERG,G.; SANDSTRÖM,R. Frequency of occlusal interferences: a clinical study in teenagers and young adults. J. prosth. Dent., v.59, n.2, p.212-7, Feb. 1988.

4. ALENCAR JÚNIOR,F.G.P. Fatores psicológicos nas disfunções craniomandibulares: estudo da relação entre graus de disfunção e escalas de ansiedade traço-estado. Bauru, 1997. 179p. Tese (Doutorado) - Faculdade de Odontologia de Bauru, Universidade de São Paulo.

5. ALMEIDA,R.R.; URSI,W.J.S. Anterior open bite: etiology and treatment. Oral Health, v.80, n.1, p.27-31, Jan.1990. 
6. ANDREWS,L. Six keys to normal occlusion. Amer. J. Orthodont., v.62, n.3, p.296-309, Sept.1972.

7. ANNANDALE,T. Displacemnt of the inter-articular cartilage of the lower jaw, and treatment by operation. Dent. Record., v.7, p. 110-2, 1887.

8. ARNOLD,J.P. Traumatic occlusion. Int. J. Orthodont., n.13, p.24-7, 1927.

9. AUSTIN,D.G.; PERTES,R.A. Examination of the TMD patient. In: PERTES,R.A.; GROSS,S.G. Clinical management of temporomandibular disorders and orofacial pain. Chicago, Quintessence, 1995. Cap.9, p.123-60.

10. BELL,W.E. Clinical management of temporomandibular disorders - classification, diagnosis, manegement. Chicago, Year Book Medical, 1982.

11. BELSER,U.C.; HANNAM,A.C. The influence of altered working-side occlusal guidence on masticatory muscles and relates jaw movement. J. prosth. Dent., v.53, n.3, p.406-13, Mar. 1985.

12 BEYRON,H. Optimal occlusion. Dent. Clin. N. Amer., n.13, p.53754, 1969. 
13. BOER,M.; STEENKS,M.H. Functional unilateral posterior crossbite. Orthodontic and functional aspects. J. oral Rehab., v.24, n.8, p.614-23, Aug. 1997.

14. BOMAN,K. Temporomandibular joint arthrosis and its treatment by extirpation of the disc. Acta Chir. Scand., Supplement n.118, 1947.

15. BONFANTE,G. et al. Redução da mordida aberta anterior através de desgaste seletivo. Rev. Odonto Pope, v.2, n.3, p.399-404, ,jul./set. 1998.

16. BUSH,F.M.; Malocclusion, masticatory muscle, and temporomandibular joint tenderness. J. dent. Res., v.64, n.2, p.129-33, Feb. 1985.

17. CLARKE,N.G. Occlusion and myofascial pain dysfunction: is there a relationship? J. Amer. dent. Ass., v.104, n.4, p.443-6, Apr. 1982.

18. COBIN,H.P. The temporomandibular syndrome and centric relation.

N. Y. St. Dent. J., n.18, p.393. 1952.

19. CONTI, P.C.R., et al. A cross-sectional study of prevalence and etiology of signs and symptoms of temporomandibular disorders in high school and university students. J. Orofac. Pain. v.10, n.3, p.254-62,1996. 
20. COSTEN, J.B. A syndrome of ear and sinus symptoms dependent upon disturbed fnctions of TMJ. Ann. Otol. (St. Louis), v.43, n.1, p.1-15, Mar. 1934.

21. COSTEN, J.B. Neuralgias and ear symptoms associated with disturbed function of the TMJ. J. Amer. med. Ass., v.107, p.252-4,1936.

22 DAHL,B.L. et al. Signs and symptoms of craniomandibular disorders in two groups of 19-year-old individuals, one treated orthodontically and other nor. Acta odont. Scand., v.46, n.2, p.89-93, Mar. 1988.

23. D'AMICO, A. Canine teeth - normal function relation of natural teeth of man. J. Calif. Dent Ass., v. 26, p.127-42, 1958.

24. DAO,T.T.T.; LUND,J.P.; LAVIGNE,G.L. Comparison of pain and quality of live in bruxers and patients with myofascial pain of the masticatory muscles. J. Orofac. Pain, v.8, n.4, p.350-56, 1994.

25. DAWSON,P.E. Temporomandibular joit pain-dysfunction can be solved. J. prosth. Dent., v.29, n.3, p.100-12, Oct. 1973.

26. DONEGAN,S.J.; CHRISTENSEN,L.V.; MC KAY,D.C. Canine tooth guidance and temporomandibular joint sounds in non-patients and patients. J. oral Rehab., v.23, n.12, p.799-804, Dec. 1996. 
27. DROUKAS,B.; LINDEE,C.; CARLSSON,G.E. Relationship between occlusal factors and signs and symptoms of mandibular dysfunction. Acta odont. Scand., v.42, n.5, p.277-83, Oct. 1984.

28. DROUKAS,B.; LINDÉE,C.; CARLSSON,G.E. Occlusion and mandibular dysfunction: Aclinical study of patients refered for functionaldisturbances of masticatory system. J. prosth. Dent., v.53, n.3, p.402-6, Mar. 1985.

29. EGERMARK,I.; RÖNNERMAN,A. Temporomandibular disorders in the active phase of orthodontic treatment. J. oral Rehab., v.22, n.8, p.613-8, Aug. 1995.

30. EGERMARK,I.; THILANDER,B. Craniomandibular disorders with special referrence to orthodontic tratment: an evaluation from childhood to adulthood. Amer. J. Orthodont. Dentofac. Orthop. v.101, n.1, p.28-34, Jan. 1992.

31. EGERMARK,I.; CARLSSON,G.E.; MAGNUSSON,T. A long-Term epidemiolgic study of the relationship between occlusal factors and mandibular dysfunction in children and adolescents. J. dent. Res., v.66, n.1, p.67-71, Jan. 1987. 
32 EGERMARK,I.; INGERVALL,B.; CARLSSON,G.E. Dependence of mandibular dysfunction in children on functional and morphologic malocclusion. Amer. J. Orthodont. Dentofac. Orthop., v.83, n.3, p.187-94, Mar. 1983.

33. EGERMARK,I. et al. A longitudinal study on maloclusion in relation to signs and symptoms of cranio-mandibular disorders and adolescents. Europ. J. Orthodont., v.12, n.4, p. 399-407, Nov. 1990.

34. FELDMANN,I.; LUNDSTRÖM,F.; PECK,S. Occlusal changes from adolescence to adulthood in untreated pacients with class II division 1 deepbite malocclusion. Angle Orthodont., v.69, n.1, p.33-8, Feb. 1999.

35. FONSÊCA,D.M. Disfunção craniomandibular (DCM) elaboração de índice anamnésico. Bauru, 1992. 116p. Dissertação (Mestrado) - Faculdade de Odontologia de Bauru, Universidade de São Paulo.

36. FONSÊCA,D.M.; BONFANTE,G.; VALLE,A.L. Diagnóstico pela anamnese da disfunção crânio-mandibular. Rev. gaúcha Odont., v.42, n.1, p.23-28, jan./fev. 1994.

37. FONSÊCA,D.M.; PAIVA, H.J.; BONFANTE, G. Temporomandibular joint clicking - clinical study. J. dent Res., v.70, n.4, p.643, Apr. 1991./Abstract n.62/ 
38. FONSÊCA,D.M. et al. Diagnóstico pela anamnese da disfunção craniomandibular. Rev. Gaúcha Odont. V.42, n.1, p.23-8, jan./fev. 1994.

39. FORSSELL,H.; KIRVESKARI,P; KANGASNIEMI,P. Response to occlusal treatment in headache patients previously treated by mock occlusal adjustment. Acta odont. scand., v.44, p.639,1986 .

40. GEERING,A.H. Occlusal interferences and functional disturbances of masticatory system. J. clin. Periodont., v.1, n.2, p.112-9, 1974.

41. GOSS, A.N. The myofascial pain dysfunction syndrome. I. Aetiology and diagnosis. N.Z.dent.J., v.70, p.192-8, July 1974.

42 GREENE,C.S. Orthodontics and temporomandibular disorders. Dent. Clin. N. Amer., v.32, n.3, p.529-38, July 1988.

43. GRIFFITHS,R.H. Report of the president's conference on examination, diagnosis and manegement of temporomandibular disorders. J. Amer. dent. Ass., v.107, n.6, p.932-6, Dec. 1983.

44. HAHN,W. Results of a clinical psychological study of diseases of the temporomandibular joint. Int. dent. J., v.29, n.4, p.260-8, 1979. 
45. HANS,M.G. et al. A comparison of clinical examination, history, and magnetic resonance imaging for identiying orthodontic patients with temporomandibular joint disorders. Amer. J. Orthodont. Dentofac. Orthop. v.101, n.1, p.54-9, Jan.1992.

46. HANSSON,T.; NILNER,M. A study of the occurrence of symptom of diseases of temporomandibular joint, masticatory musculature and relates structures. J.oral Rehab., v.2, n.4, p.313-24, Oct. 1975.

47. HEIKINHEIMO,K. et al. A longitudinal study of occlusal interferences and signs of craniomandibular disorder at the ages of 12 and 15 years. Europ. J. Orthodont. v.12, n.2, p.190-7, May 1990.

48. HELKIMO,M. Studies on function and dysfunction of the masticatory system. I - an epidemiological investigation of syntoms of dysfunction in lapps in north of Finland. Proc. Finn. Dent. Soc., v.70, n.4, p.37-49, Apr. 1974.

49. HELKIMO,M. Studies on function and dysfunction of the masticatory system. II - Index for anamnetic and clinical dysfunction and occlusal state. Sven Tandlak Tidskr., v.67, n.2, p.101-21, Mar. 1974. 
50. HELKIMO,M. Studies on function and dysfunction of the masticatory system. III - Analyses of anamnesic and clinical recordings of dysfunction with the aid of indices. Sven Tandlak Tidskr., v.67, n.3, p.165-81, May 1974.

51. HELKIMO,M. Studies on function and dysfunction of the masticatory system. IV - age and Sex distribuition of symptoms of dysfunction of the masticatory system in lapps in the north of Finland. Acta odont. Scand., v.32, n.4, p.255-67, 1974.

52 HELÖE,B.; HELÖE,L. A. Frequency and distribution of myofascial pain dysfunction syndrome in a population of 25-year-olds. Community Dent. oral epidem., v.7, n.6, p.357-60, 1979.

53. HENRIKSSON,T.; EKBERG,E.C.; NILNER,M. Symptoms and signs of temporomandibular disorders in girls with normal occlusion and class II maloclusion. Acta odont. Scand., v.55, n.4, p.22935, Aug. 1997.

54. HENRIKSSON,T.; EKBERG,E.C.; NILNER,M. Masticatory efficiency and ability inrelation and mandibular dysfunction in girls. Int. J. Prosthodont., v.11, n.2, p.125-32, Mar./Apr. 1998.

55. HWANG,H.S.; BEHRENTS,R.G. The effect of orthodontic treatment on centric discrepancy. J. Cranio Practice. , v.14, n.2, p.132-7, Apr. 1996. 
56. INGERVALL,B.; CARLSSON,G.E. Masticatory muscle activity before and elimination of balancing side occlusal interference. J. oral Rehab., v.9, n.3, p.183-92, May 1982.

5. JANSON,G.R.P.; MARTINS,D.R. Análise funcional e ajuste oclusal em ortodontia: estudo clínico. Ortodontia, v.23, n.1, p.4-15. 1990.

58. JANSON,G.R.P. et al. Oclusão funcional e ajuste oclusal. IN: VIAZIS,A.D. Ortodontia avançada: um guia para a eficiência clínica. São Paulo, Santos, 1999.

59. KAHN,J. et al. Prevalence of dental occlusal variables and intraarticular temporomandibular disorders: molar relationship, lateral guidance, and nonworking side contacts. J. prosth. Dent., v.82, n.4, p.410-5, Oct.1999.

6. KEB,K.; BAKOPULOS,K.; WITT,E. TMJ function with and without orthodontic treatment. Europ. J. Orthodont. v.13, n.3, p.192-6, June 1991.

61. KEELING,S.D. et al. Risk factors associated with temporomandibular joint in children 6 to 12 years of age. Amer. J. Orthodont. Dentofac. Orthop., v.105, n.3, p.279-87, Mar. 1994. 
6 KIRVESKARI,P.; ALANEN,P.; JÄMSÄ,T. Association between cranimandibular disorders and occlusal interferences. J. prosth. Dent., v.62, n.1, p.66-9, July 1989.

6. KORIOTH.T.W.P. Number and location of occlusal contacts in intercuspal position. J. prosth. Dent., v.64, p.206-10, 1990.

64. KREMNAK,C.R. et al. Orthodontic risk factors for temporomandibular disorders (TMD). II. Am. J. Orthodont. Dentofac. Orthop. v.101, n.1, p.21-7, Jan. 1992.

65. LASKIN,D.M. Etiology of the pain-dysfunction syndrome. J. Amer. dent. Ass., v.79, n.6, p.147-53, July 1969.

66. LIEBERMAN,M.A. et al. Mandibular dysfunction in 10-18 year old school children as related to morphological malocclusion. J. oral Rehab., v.13, n.3, p.209-14, May/June 1985.

67. LINDHE,J.; NYMAN,S. The role of oclusion in periodontal disease and the biological rationale for splinting in the treatment of periodontatis. Oral Sci. Ver. N.10, p.11-43. 1977.

68 LIPP, M.J. Temporomandibular symptoms and occlusion: a review of the literature e the concept. N. Y. St. Dent. J., p.58-66, Nov. 1990. 
69. LIVINGSTON,W. Moving teeth and raiving eyehrows. Funct. Orthodont., v.5, p.21-4. 1988.

70. LONG,J.H. Locating centric relation with a leaf gauge. J. prosth. Dent., v.29, p. 608-10, 1973.

71. LUCIA,V.O. Centric relation: theory and practice. J. prosth. Dent., v.10, p.849-56, 1960.

72 LUTHER,F.; MORTH,M.S. Orthodontics and the temporomandibular joit: where are we now? Part 2. Functional occlusion, malocclusion, and TMD. Angle Orthodont., v.68, n.4, p.305-18, Aug. 1998.

73. MAGNUSSON,T.; ENBON, L. Signs and symptoms of mandibular dysfuncyion aafter introduction of experimental balancing-side interferences. Acta odont. Scand., v.42, p.129-35, 1984.

74. MAGNUSSON,T.; CARLSSON,G.E.; EGERMARK,I. Changes in clinical signs of craniomandibular disorders from the age of 15 to 25 years. J. Orofac. Pain, v.8, n.2, p.207-15, Spring 1994.

75. MAGNUSSON,T.; EGERMARK,I.; CARLSSON,G.E. Five-year longitudinal study of signs and symptoms of mandibular dysfunction in adolescents. J. craniomandibular pratc., v.4, n.4, p.339-43, Oct.1986. 
76. MCNAMARA JÚNIOR, J.A.; SELIGMAN,D.A.; OKESSON,J.P. Occlusion, orthodontic treatment, and temporomandibular disorders: a review. J. Orofac. Pain., v.9, n.1, p.73-90, Winter 1995.

77. MCNEILL,C. Craniomandibular (TMJ) disorders - the state of the art. J. prosth. Dent., v.44, p.434, 1980.

78. MCNEILL,C. Craniomandibular disorders - guidelines for evaluation, diagnosis, and management / The American Academy of Craniomandibular disorders. Chicago, Quintessence, 1990.

79. MCNEILL, C. Ciência e prática da oclusão. São Paulo, Quintessence, 2000.

80. MIKHAIL,M., ROSEN,H., History and etiology of myofascial pain dysfunction syndrome. J. prosth. Dent., v.44, n.4, p.438-44, Oct. 1980.

81. MOHLIN,B. Prevalence of mandibular dysfunction and relation between malocclusion and mandibular dysfunction in a group of women in sweden. Europ. J. Orthodont., v.4, p.115-23, 1983.

82 MOHLIN,B.; KOPP,S.A. A clinical study of symptoms of mandibular dysfunction in young Swedish men. Swed. dent J., v.2, p.10512, 1978. 
83. MOHLIN, B.; INGERVALL,B.; THILANDER,B. Relation between malocclusion and mandibular dysfunction in Swedish men. Europ. J. Orthodont., v.2, n.4, p.229-38, 1980.

84. MOLIN,C. et al. Frequency of symptoms of mandibular dysfunction in young swedish men. J. oral Rehab., v.3, n.1, p.9-18, Jan. 1976.

85. NILNER,M. Relationships between oral parafunctions and functional disturbances and diseases of the stomatognathic system among children aged 7-14 years. Acta odont. Scand., v.41, p.167-72,1983.

86. NILNER,M. Relationships between oral parafunctions and functional disturbances and diseases of the stomatognathic system among 15 - to - 18 year olds. Acta odont. scand., v.41, p.197-201, 1983.

87. OKESON,J.P. Etiology and treatment of occlusal pathosis and associated facial pain. J. prosth. Dent., v.45, n.2, p.199-204, Feb. 1981.

88. OKESON,J.P. Fundamentos de oclusão e desordens têmporomandibulares. 2.ed. São Paulo Artes Médicas, 1992.

89. OLSSON,M.; LINDQVIST,B. Mandibular function before orthodontic treatment. Europ. J. Orthodont., v.14, n.1, p.61-8, Feb. 1992. 
90. PERRY JÚNIOR,H.T. Adolescent temporomandibular dysfunction. Amer. J. Orthodont., St. Louis, v.63, n.5, p.517-25, May 1973.

91. PRINGLE,J.H. Displacement of mandibular meniscus and its treatment. Brit. J. Surg., v.6, p.385-9, 1918.

92 PULlingeR,A.G.; SELIGMAN,D.A. Overbite and overjet characteristics of refined diagnostic groups of temporomandibular disorder patients. Amer. J. Orthodont. Dentofac. Orthop., v.100, n.5, p.401-15,1991.

93. PULLINGER,A.G.; SELIGMAN,D.A. The degree to which attriton characterizes differentiated patient groups of temporomandibular disorders. J. Orofac. Pain., v.7, n.2, p.196208, 1993.

94. PULLINGER,A.G.; SELIGMAN,D.A. Quantification and validation of predictive values of occlusal variables in temporomandibular disorders using a multifactorial analysis. J. prosth. Dent., v.83, n.1, p.66-75, Jan. 2000.

95. PULLINGER,A.G.; SELIGMAN,D.A.; SOLBERG,W.K. Temporomandibular disorders. Part II: occlusal factors associated with temporomandibular joint tenderness and dysfunction. J. prosth. Dent., v.59, n.3, p.363-7, Mar. 1988. 
96. PULLINGER,A.G. et al. Relationship of mandibular condylar position to dental occlusion factors in na asymptomatic population. . Amer. J. Orthodont. Dentofac. Orthop., v.91, n.3, p.200-6, Mar. 1987.

97. RENDELL,J.K.; NORTON,L.A.; GAY,T. Orthodontic treatment and temporomandibular joint disorders. Amer. J. Orthodont. Dentofac. Orthop., v.101, n.1, p.84-7, Jan. 1992.

98. RICKETTS,R.M. Abnormal function of the temporomandidular joint. Amer. J. Orthodont., v.41, p.435-31, 1955.

99. RICKETTS,R.M. Clinical implications of the temporomandibular joint.). Amer. J. Orthodont., St. Louis, v.52, n.6, p.416-38, June 1966.

100. RIEDER,C.E. The prevalence and magnitude of mandibular displacement in a survay population. J. prosth. Dent., v.39, n.4, p.324-9, Apr. 1978.

101. RIEDER,C.E. Maximum mandibular opening in patients with and without a history of TMJ dysfuncyon. J. prosth. Dent., v.39, n.4, p.441-6, Apr. 1978. 
102 RIEDER,C.E.; MARTINOFF, J.T.; WILCOX,S.A. The prevalence of mandibular dysfunction. Part I: Sex and age distribution of related signs and symtoms. J. prosth. Dent., v.50, n.1, p.81-8, July 1983.

103. RIISE,C.; ERICSSON,S.G. A clinical study of occlusal tooth contacts in the intercuspal position at ligth and hard pressure in adults. J. oral Reab., v.10, n.6, p.473-80, Nov. 1983.

104. RIOLO,M.L.; BRANDT,D.; TENHAVE,T.R. Associations between occlusal characteristics and signs amd symptoms of TMJ dysfunction in children and young adults. Amer. J. Orthodont. Dentofac. Orthop., v.92, n.6, p.467-77, Dec. 1987.

105. RUGH,J.D.; SOLBERG,W.K. Oral health status in the United States: temporomandibular disorders. J. dent. Educ., v.49, n.6, p.398-405, June 1985.

106. SADOWSKY,C. The risk of orthodontic treatment for producing temporomandibular mandibular disorders: a literature overview. Amer. J. Orthodont. Dentofac. Orthop., v.101, n.1, p.79-83, Jan. 1992.

107. SADOWSKY,C.; BEGOLE,E.A. Long-term status of temporomandibular joit function and functional acclusion after orthodontic treatment. Amer. J. Orthodont. Dentofac. Orthop., v.78, n.2, p.201-12, Aug. 1980. 
108. SADOWSKY,D.; POLSON,A.M. Temporomandibular disorders and functional occlusion after orthodontic treatment: results of two long-term studies. Amer. J. Orthodont. Dentofac. Orthop., v.86,n.5, p.386-90, Nov.1984.

109. SCHIFFMAN,E.L. et al. The prevalence and treatment needs of subjects with temporomandibular disorders. J. Amer. Dent. Ass., v.120, n.3, p.295-303, 1990.

110. SCHWARTZ,L. Pain associated with the temporomandibular joint. J. Amer. dent. Ass., v.51, n.10, p.394-401, Oct. 1955.

111. SELIGMAN,D.A.; PULLINGER,A.G. The role of intercuspal occlusal relationship in temporomandibular disorders: a review. J. craniomandibular dis. fac. oral pain., v.5, n.2, p.96-106, 1991.

112 SELIGMAN,D.A.; PULLINGER,A.G. The role of funcional occlusal relationship in temporomandibular disorders: a review. J. craniomandibular dis. fac. oral pain., v.5, n.4, p.265-79, 1991.

113. SELIGMAN,D.A.; PULLINGER, A.G.; SOLBERG,W.K. Temporomandibular disorders. Part III: occlusal and articular factors associated with muscle tenderness. J. prosth. Dent., v.59, n.4, p.483-9, Apr. 1988. 
114. SELIGMAN,D.A.; PULLINGER,A.G.; SOLBERG,W.K. The prevalence of dental attrition and its association with factors of age, gender, ocluson and tmj symptolatology. J. dent. Res., v.67, n.10, p. 1323-33, Oct. 1988.

115. SICHER,H. Temporomandibular articulation in mandibular overclosure. J. Amer. dent. Ass., v.36, n.2, p.131-9, Feb. 1948.

116. SOLBERG,W.K. TMD - phsysical test in diagnosis. Brit. Dent. J., v.160, n.4, p.273-7, Apr. 1986.

117. SOLBERG,W.K.; FLINT,R.T.; BRANTNER,J.P. Temporomandibular joint pain and dysfunction: a clinical study of emotional and occlusal components. J prosth. Dent., v.28, n.4, p.412-22, Oct.1972.

118. SOLBERG,W.K.; WOO,M.W.; HOUSTON,J.B. Prevalence of mandibular dysfunction in young adults. J. Amer. dent. Assoc., v.98, n.1, p.25-34, Jan. 1979.

119. TEIXEIRA,A.C.B.; MARCUCCI,G.; LUZ,J.G.C. Prevalência das má oclusões e dos índices anamnésicos e clínicos, em pacientes com disfunção da articulação temporomandibular. Rev. Odont. USP., v.13, n.3, p.251-6, jul./set. 1999. 
120. TIMM,T.A. et al. Occlusion and orthodontics. Amer. J. Orthodont., v.70, p.138-45, 1976.

121. VLACHOS,C.C. Occlusal principles in orthodontics. Dent. Clin. N. Amer. V.39, n.2, Apr. 1995.

122 WADHWA,L.; UTREJA,A.; TEWARI,A. A study of clinical signs and symptoms of temporomandibular dysfunction in subjects with normal occlusion, untreated, and treated maloclusions. Amer. J. Orthodont. Dentofac. Orthop., v.103, n.2, p.54-61, Jan. 1993.

123. WÄNMAN,A. Crabiomandibular disorders in adolescents. A longitudinal study in a urban Swedish population. Swed. Dent. J., v.44, p.1-61, 1987.

124. WÄNMAN,A.; AGERBERG,G. Etiology of craniomandibular disorders: evaluation of some occlusal and psychosocial factors in 19-year-olds. J. craniomandibular dis. fac. oral pain, v.5, n.1, p.35-44, 1990.

125. WIGDOROWICZ-MAKOWEROWA, N. et al. Epidemiologic studies on prevalence and etiology of functional disturbances of the masticatory system. J. prosth. Dent., v.41, n.1, p.76-82, Jan. 1979. 
Abstract 


\section{ABSTRACT}

The aim of this study was to evaluate the prevalence of Temporomandibular Disorders (TMD) in individuals with and without orthodontic treatment. Sample was composed of 200 individuals divided into four groups, according to the type of malocclusion (Angle's Class I or II) and the accomplishment of orthodontic treatment. The presence of signs and symptoms of TMD were evaluated by an anamnestic questionnaire and a clinical examination, including TMJ and muscle palpation, active mandibular range of motion and joint noises. The occlusal examination included analysis of contacts in intercuspal position (IP) and retruded contact position, presence of lateral and anterior guidance and non-working side contacts. Anterior open bite, posterior cross bite, overjet, ovebite, occlusal ajustment and dental attrition were also evalueted. Based on the anamnestic questionnaire, 34\% was considered as having mild TMD, while $3.5 \%$ had moderate TMD. The presence and severity of TMD have not shown any relationship with type

of malocclusion and/or accomplishment of orthodontic treatment. A positive association was found between TMD and absence of anterior guidance. Based on that, it was concluded that orthodontic treatment is not associated with the presence of signs and symptoms of TMD neither occlusion can be defined as a primary etiologic factor for TMD. 